\title{
DEL PATRIMONIO AL TESTIMONIO: EL PROYECTO "IN BETWEEN?" Y LA MEMORIA DEL EXILIO REPUBLICANO
}

\author{
From heritage to testimony: the "In Between?" project \\ and the memory of the republican exile
}

\section{David González Vázquez}

Observatorio Europeo de Memorias - Universidad de Barcelona david.gonzalez@ub.edu Orcid: 0000-0003-0184-091X

Ricard Conesa Sánchez

Observatorio Europeo de Memorias - Universidad de Barcelona rconesa@ub.edu Orcid: $\underline{0000-0002-5384-6857}$

\section{Jordi Guixé Corominas}

Observatorio Europeo de Memorias - Universidad de Barcelona jordiguixe@ub.edu Orcid: 0000-0003-3060-764X

Cómo citar este artículo/Citation:

David González Vázquez, Ricard Conesa Sánchez y Jordi Guixé Corominas, "Del patrimonio al testimonio: el proyecto "in between?" y la memoria del exilio republicano", Hispania Nova, 1 Extraordinario (2021): 81 a 121.

DOI: https://doi.org/10.20318/hn.2021.6180

\begin{abstract}
Copyright: (C) HISPANIA NOVA es una revista debidamente registrada, con ISSN 1138-7319 y Depósito Legal M 9472-1998. Los textos publicados están -si no se indica lo contrario- bajo una licencia Reconocimiento-Sin obras derivadas 3.0 España de Creative Commons. Puede copiarlos, distribuirlos y comunicarlos públicamente siempre que cite su autor y la revista y la institución que los publica y no haga con ellos obras derivadas. La licencia completa se puede consultar en: http://creativecommons.org/licenses/by-nd/3.0/es/deed.es
\end{abstract}


Resumen: El continuo desarrollo de las nuevas tecnologías, una política patrimonial focalizada en los lugares de memoria del exilio republicano español y el desarrollo de nuevas redes internacionales que promueven proyectos vinculados a la memoria colectiva en Europa, ha permitido que surjan nuevas experiencias colaborativas como el proyecto "In Between?". Impulsado por la European Network Remembrance and Solidarity (ENRS) y dirigido a jóvenes estudiantes de toda Europa, una de las ediciones de este proyecto fue realizada en la frontera francoespañola. Distintos estudiantes de diferente nacionalidad compartieron una experiencia de investigación y recogida de datos de varios espacios memoriales y testimonios del exilio republicano español, una memoria que ha marcado para siempre diferentes municipios alrededor de la frontera, creando una identidad singular.

Palabras clave: memoria, frontera, exilio republicano, Retirada, Pirineos

\begin{abstract}
The continuous development of new technologies, a patrimonial policy focused on places of memory of the Spanish republican exile and the development of new international networks that promote projects linked to collective memory in Europe, has allowed new collaborative experiences to emerge, such as the "In Between?". Promoted by the European Network Remembrance and Solidarity (ENRS) and aimed at young students from all over Europe, one of the editions of this project was carried out on the Franco-Spanish border. Different students of different nationalities shared an experience of research and data collection from various memorial spaces and testimonies of the Spanish republican exile, a memory that has forever marked different municipalities around the border, creating a unique identity.
\end{abstract}

Keywords: memory, border, Republican exile, Retirada, Pyrenees

\section{INTRODUCCIÓN}

El exilio republicano español o "la Retirada" (tal y como se conoce en territorio francés al éxodo masivo de aproximadamente medio millón de personas que huían tras la ocupación franquista de Cataluña hacia el país galo), es el principal evento histórico constitutivo de memoria colectiva existente en la frontera pirenaica. Memoria traumática, obviamente, pues conlleva el recuerdo de episodios tan nefastos como una huida forzada con frío, hambre y miseria, y una paupérrima acogida en los campos de internamiento improvisados por el gobierno francés, y el posterior devenir de resistencia y deportación ${ }^{1}$.

Un exilio republicano que, sin proponérselo, y tras el bagaje que supuso la Guerra Civil española, tendría su destino ligado al de los medios de difusión gráficos del momento. El recién nacido fotoperiodismo daría buena cuenta de la experiencia, y convertiría al exilio republicano español en el primer gran éxodo poblacional con

\footnotetext{
${ }^{1}$ Uno de los estudios más completos sobre el exilio republicano español en Francia en Geneviève Dreyfus-Armand, El exilio de los republicanos españoles en Francia (Barcelona: Crítica, 2000).
} 
cobertura mediática. De ello se encargaron las principales agencias periodísticas a nivel global, que en aquellos turbulentos días establecieron su base en la ciudad de Perpignan $^{2}$.

La memoria de aquellos hechos, de igual manera que la denominada "memoria histórica" en el conjunto de España, ha aflorado en el territorio a partir de los años 90 del siglo XX. La frontera francoespañola en su vertiente más oriental, posfrontera en este caso tras la eliminación de las fronteras políticas en el espacio Schengen en 1995, es considerada como una de las más impermeables de Europa ${ }^{3}$. Es decir, que aun sin la existencia de la frontera política, perviven de manera consuetudinaria comportamientos socioculturales de división propios de la anterior etapa, así como un arraigado contexto de control policial. Pese a ello, la memoria del exilio republicano ha emergido a ambos lados de la frontera, y puede ser considerada como una de las principales conexiones culturales entre ambas zonas ${ }^{4}$.

Los territorios de frontera tienen sus propias particularidades. Así, la frontera siempre ha de representar una dualidad entre lo bueno y lo malo, entre el reencuentro y la despedida, entre la unión y el conflicto ${ }^{5}$. Como elemento histórico de referencia, su destino será siempre el de modificar su tamaño, ubicación y magnitud social ${ }^{6}, \mathrm{y}$, aunque mute y evolucione, la frontera evoca y evocará con frecuencia hechos excepcionales de marcado carácter emocional ${ }^{7}$. Tales son los hechos históricos que en este territorio de frontera son susceptibles de constituir una memoria colectiva, tan poderosos en lo emocional como relevantes en lo analítico. Partiendo de la base del exilio republicano como la estructura histórica y memorial de referencia, su abordaje permite el estudio y análisis de elementos tales como el fascismo, la revolución, la Guerra Civil, la

\footnotetext{
${ }^{2}$ Eric Forcada, De la chute de Barcelone à la Retirada : Report of Wide World Photo for the New York Times. (Perpignan: Mare Nostrum, 2014).

${ }^{3}$ Enric Pujol, "El Cas Català com a Paradigma", Mirmanda, n³, (2008): pp. 26-28.

${ }^{4}$ Enric Pujol, "Projectes culturals transfronterers: el cas de l'exili republicà de 1939". Mirmanda, n4, (2009): pp. 74-84

${ }^{5}$ Michel Foucher, Fronts et Frontiers: Un Tour du Monde Géopolitique. (Paris: Fayard, 1991)

${ }^{6}$ Karl Schlögel, En el Espacio Leemos el Tiempo: Sobre la Historia de la Civilización y Geopolítica. (Madrid: Ediciones Siruela, 2007)

${ }^{7}$ Martine Camiade, "Territori, Paisatge i Exili. Rosselló 1939: Allò Viscut d'una Crisi Humanitària a partir de les Fonts Orals". Dir. por Jordi Font, Reflexionant l'Exili: Aproximació a l'Exili Republicà: Entre la Historia, l'Art $i$ el Testimoniatge (Catarroja: Editorial Afers, 2010), pp: 49-62.
} 
democracia, la resistencia nacional y cultural catalana, los campos de internamiento y sus condiciones de vida, la Segunda Guerra Mundial, los refugiados, la deportación, los derechos humanos, y otros tantos componentes analíticos que se desprenden de la mencionada estructura base que supone el exilio republicano.

Así, existe hoy día una importante topografía memorial de lugares que, a un lado y a otro de la frontera pirenaica, ejercen como difusores de la memoria del exilio republicano y las diferentes evocaciones de ella desprendidas. Museos, centros de interpretación, rutas y señalizaciones, placas, monumentos, son las marcas territoriales ${ }^{8}$ de la memoria que interpelan a ese pasado $\mathrm{y}$, atendiendo a los diferentes grados de valorización de sus elementos, lo difunden, interpretan o analizan.

Del mismo modo, convivimos actualmente con un contexto de constante actualización de los avances tecnológicos, lo cual conlleva una revisión entre las diferentes maneras de relación existentes entre dichos avances y los elementos patrimoniales, en general, y memoriales, en particular. En este aspecto, resulta prácticamente inconcebible el mundo cultural y patrimonial sin la influencia que ejerce hoy día el entorno digital ${ }^{9}$. A nivel de educación patrimonial, tampoco se concibe un ámbito pedagógico solvente, y adaptado a las necesidades y retos de los nuevos tiempos, si no es mediante el uso de las herramientas digitales a disposición de los visitantes ${ }^{10}$. En el caso de los dispositivos móviles y sus diversas utilidades en el ámbito educativo, se percibe este avance incluso como una auténtica revolución ${ }^{11}$.

A la par de estos avances tecnológicos alrededor del mundo digital y sus diferentes usos patrimoniales y educativos, encontramos también la emergencia de nuevos usos sociales en el marco de la comunicación que influyen severamente en el desarrollo de nuevas líneas de trabajo en el mundo digital. Tal sería el caso de las redes

\footnotetext{
${ }^{8}$ Elizabeth Jelin y Victoria Langland (Comps.) Monumentos, memoriales y marcas territoriales. (Madrid - Buenos Aires: Siglo XXI, 2003).

9 Victoria López Benito y Joan Santacana Mestre, “Cultura digital, museos y educación”, Her\&Mus. Heritage \& Museography, n. ${ }^{\circ} 13, \quad$ (2013): pp. $8-15 . \quad$ URL: https://www.raco.cat/index.php/Hermus/article/view/313342 [Consulta: 9-10-2020]

${ }^{10}$ Laia Coma Quintana, "Dinamizar y digitalizar la ciudad: itinerarios urbanos, dispositivos móviles y códigos QR". Her\&Mus. Heritage \& Museography, n. ${ }^{\circ} 13, \quad$ (2013): pp. 63-68. URL: https://www.raco.cat/index.php/Hermus/article/view/313395 [Consulta: 9-10-2020]

11 T.H. Brown, "Beyond constructivism: navigationism in the knowledge era", On the Horizon, nº14, (2006): pp. 108-120.
} 
sociales, un útil al abasto de las nuevas generaciones que supone una de las principales herramientas existentes para el aprendizaje de cuestiones relativas a la memoria y a la historia. Las redes sociales en la actualidad son, de hecho, una herramienta poderosísima para la transmisión de la memoria ${ }^{12}$, como atestiguan casos como el del proyecto \#Souvenirs1936, en el cual el alumnado de Bachillerato de un Instituto de Valladolid realiza una aproximación al conocimiento de la Guerra Civil española a través de la construcción de los recuerdos de algunos protagonistas ${ }^{13}$.

Ante este contexto, donde confluyen una rica y extensa representación de elementos patrimoniales ligados a la memoria del exilio y una emergente relevancia de los entornos digitales en el tratamiento de dicha memoria, se ubica el presente artículo y el estudio de caso en él presentado: el proyecto "In Between?" y su edición en el territorio catalán transfronterizo ${ }^{14}$. Así, en los siguientes apartados, se presentarán los diferentes lugares de memoria del exilio republicano ubicados a ambos lados de la cordillera pirenaica, los cuáles sirvieron de inspiración y apoyo contextual durante la semana de realización del proyecto dedicada al trabajo de campo. Asimismo, se expondrán los puntos básicos sobre la epistemología y metodología del proyecto "In Between?", y las particularidades concretas que tuvo el desarrollo de la edición realizada en la frontera oriental francoespañola.

\section{LOS ESPACIOS DE MEMORIA DEL EXILIO REPUBLICANO: UN PATRIMONIO TRANSFRONTERIZO}

La Guerra Civil española ha trascendido hasta nuestros días legándonos un importante cúmulo de vestigios patrimoniales, tan amplio como diverso y disperso. En el conjunto de España existen elementos patrimoniales, de carácter material e

\footnotetext{
${ }^{12}$ Matilde Eiroa San Francisco, "Memoria e historia en redes sociales: nuevos soportes de resistencia al olvido de la Guerra Civil española y el Franquismo". Historia y memoria, n²1, (2020): pp. 71-108. DOI: https:/doi.org/10.19053/20275137.n21.2020.9659

${ }^{13}$ Pablo De Castro Martín y Inmaculada Sánchez-Macías, “\#Souvenirs1936. Transmedia y procesos de identización en el aprendizaje”, Revista Interuniversitaria de Formación del Profesorado, n94, (2019): pp. 63-82.

${ }^{14}$ El territorio (o espacio) catalán transfronterizo, es la zona comprendida por la provincia española de Girona y el departamento francés de los Pirineos Orientales. Se trata de una categorización dentro del marco de la Euroregión Pirineos Mediterráneo, de la cual forman parte las CC.AA. españolas de Cataluña e Islas Baleares, junto con la región francesa de Occitania. En el contexto del presente artículo se toma como referencia para referirnos a la frontera francoespañola en su vertiente más oriental.
} 
inmaterial, que se manifiestan en función del papel desempeñado en su día durante el conflicto. Así, aquellos lugares que fueron frente durante largo tiempo disponen de un considerable patrimonio bélico, de igual manera que los espacios de retaguardia disponen de vestigios relacionados con la defensa civil o con la represión, entre otras tipologías. El caso de Cataluña resulta bastante paradigmático en este sentido, puesto que, pese a ejercer como retaguardia casi durante todo el conflicto, dispone de elementos bélicos de primer orden dispersados por lo que fueron los frentes del Segre y del Ebro. Los bombardeos y la defensa antiaérea activa y pasiva, la defensa costera, los campos de aviación o incluso las reminiscencias de la Guerrilla son elementos que, por el contrario, ponen a Cataluña también como referente del patrimonio ligado a la retaguardia.

Hablar del exilio es hacerlo de una categoría patrimonial muy concreta, y también muy concentrada a nivel geográfico. A través del territorio catalán se vehiculó el grueso del exilio terrestre provocado por la caída de los frentes del Ebro y del Segre, en noviembre de 1938 y enero de 1939 respectivamente. El proceso histórico conocido con el nombre de exilio republicano hace referencia a la avalancha de refugiados que huyeron rumbo a Francia tras la caída de los mencionados frentes. Así, entre finales de enero y principios de febrero de 1939, los pasos de La Jonquera, Portbou, Puigcerdà, Coll d'Ares, y otros tantos no tan conocidos, se vieron masificados y congestionados por el paso de aquellas personas que huían de la ocupación franquista. A nivel cuantitativo, se cifra este contingente en aproximadamente medio millón de personas.

La memoria de aquellos hechos ha resurgido con fuerza en el contexto del conocido como proceso de recuperación de la memoria histórica en España, cuyo inicio tiende a señalarse con la primera exhumación científica de una fosa común de represaliados republicanos ${ }^{15}$. Dicho proceso ha permitido la activación social y política necesaria para otorgar un papel relevante a la memoria de la Guerra Civil y de la dictadura en España. La mencionada exhumación tuvo lugar en Priaranza del Bierzo, provincia de León, en el año 2000. Desde entonces, se conoce a las 13 personas cuyos cadáveres fueron exhumados como "los 13 de Priaranza". A lo largo de la primera

\footnotetext{
15 Emilio Silva, "Movimiento memorialista (El contexto de la memoria)". Ed. Por Rafael Escudero, Diccionario de memoria histórica. Conceptos contra el Olvido (Madrid: Los Libros de la Catarata, 2011), pp. 69-75.
} 
década del nuevo siglo, las diferentes iniciativas del creciente movimiento asociativo por la recuperación de la memoria histórica acabaron comportando consecuencias legislativas, como la aprobación de la llamada "Ley de memoria histórica" (Ley $52 / 2007)^{16}$. En semejante contexto, catalogable como "momento memoria" ${ }^{17}$ por el mencionado impacto del mundo asociativo y el creciente despertar académico y divulgativo, ubicamos también el despertar de su impacto a nivel patrimonial. De esta manera, el mundo de la cultura, de la educación, e incluso del patrimonio y el turismo, entraban a formar parte del circuito de elementos que daban cobertura a la llamada memoria histórica en España ${ }^{18}$.

Pese a disponer de un contexto plenamente democrático desde el final de la Segunda Guerra Mundial, la memoria de "la Retirada" permaneció en Francia relegada a la periferia de la historia y la memoria oficiales. La siempre tratada como heroica resistencia francesa, de la cual muchos exiliados españoles formaron parte, es la protagonista de un relato memorial donde aspectos como el colaboracionismo, o el controvertido trato recibido por los exiliados españoles por gran parte de las instituciones del país, pasan casi desapercibidos. Tal y como sucede en el caso español, será la propia sociedad civil, organizada en diversas entidades de tipo memorial, la encargada de reivindicar la memoria del exilio republicano en territorio francés. Dichas entidades se componen en su mayor parte de los descendientes de aquellos exiliados que cruzaron los Pirineos el año 1939 y que, en muchos casos, jamás volverían a España. A finales de la década de los cuarenta, unos cien mil refugiados españoles residían en Francia. Viendo que la dictadura perduraría, muchos decidieron quedarse mientras otros prefirieron volver de forma escalonada. Los refugiados que decidieron quedarse en Francia (la gran mayoría) gozaban de una red social muy fuerte, con más de ciento sesenta entidades políticas y culturales, con sus boletines y diarios, repartidas sobre todo

\footnotetext{
16 Se conoce como Ley de Memoria Histórica a la Ley 52/2007, de 26 de Diciembre, por la que se reconocen y amplían derechos y se establecen medidas a favor de quienes padecieron persecución o violencia durante la guerra civil o la dictadura, $\mathrm{BOE} \mathrm{n}^{\mathrm{0}} 310$, p. 53.410 (2007).

17 Ismael Saz, "El "moment memòria". Justícia, veritat i reconciliació democràtica", Afers: fulls de recerca i pensament, Vol. 22, nº56, (2007): pp. 27-40

${ }^{18}$ David González Vázquez, "La práctica turística como mecanismo de transmisión de valores: Cataluña y los lugares de memoria democrática", RITUR - Revista Iberoamericana de Turismo, n4 especial, (2014): pp. 36-49; y David González Vázquez, "La patrimonialización de la memoria histórica: entre el deber social y la estrategia turística. Apuntes sobre el caso catalán”, PASOS - Revista de Patrimonio y Turismo Cultural, vol. 5, nº14, (2016): pp. 1267-1280
} 
en el sur del hexágono, muy politizadas, aunque también muy divididas ${ }^{19}$. La experiencia de la llegada y la pervivencia en Francia, se convirtió en el núcleo de una nueva e inventada identidad colectiva dentro de estos colectivos ${ }^{20}$.

El Departamento francés de los Pirineos Orientales, conocido popularmente como la Cataluña Norte, ejerció como principal territorio de acogida para una gran mayoría de los republicanos exiliados. Se trata de un territorio que, a través de elementos históricos y socioculturales, presenta numerosas características comunes con respecto a Cataluña. El exilio republicano, desde entonces, pasa a sumarse a la lista de nexos existentes a norte y sur de la frontera pirenaica, y la memoria del exilio es actualmente una importante herencia compartida ${ }^{21}$.

El año 2007 nace en Cataluña el Memorial Democràtic, la institución a cargo de la promoción y ejecución de las políticas públicas de memoria a nivel autonómico. Entre sus diversas funciones, se encuentra la de identificar, catalogar y clasificar todos aquellos espacios relativos a la memoria democrática del territorio. A partir de entonces, un patrimonio que llevaba décadas en el olvido pasaba poco a poco a ganar reconocimiento y a asentarse dentro de la oferta cultural existente en Cataluña.

La consolidación de las políticas públicas de memoria en Cataluña implicó que la memoria democrática adquiriera la categoría de patrimonio ${ }^{22}$, cuyo ámbito cronológico quedaría delimitado entre los años 1931 y 1980. Dentro de dicha referencia cronológica se ubicarían 4 etapas históricas diferenciadas: la Segunda República, La Guerra Civil, la dictadura franquista y la transición democrática. A nivel estructural, por su parte, se establecía la Red de espacios de memoria democrática de Cataluña, que, a su vez, se estructuraría de manera organizativa y temática ${ }^{23}$.

\footnotetext{
${ }^{19}$ Dreyfus-Armand, El exilio de los republicanos.... p. 229

${ }^{20}$ Federica Luzi, "Entre narrations et expériences. Les uages du passé des réfugiés espagnols en France". (Tesis doctoral, París - EHESS, 2016). URL: http://www.theses.fr/2016EHES0723

${ }^{21}$ Enric Pujol, "Projectes culturals transfronterers: el cas de l'exili republicà de 1939”, Mirmanda, n4, (2009): pp. 74-84

22 Ricard Vinyes, "La memoria del Estado", dir. por Ricard Vinyes, El Estado y la memoria: gobiernos y ciudadanos frente a los traumas de la historia (Barcelona: RBA Libros, 2009), pp. 23-66; y Ricard Vinyes, "Memoria, democracia y gestión”, História e Perspectivas, nº54, (2016): pp. 11-22

23 Jordi Guixé, "El Memorial Democrático y los lugares de la memoria: la recuperación del patrimonio memorial en Cataluña", Entelequia, n7, (2008): pp. 217-228; y Jordi Guixé "Espacios, memoria y
} 
A nivel organizativo, los elementos pertenecientes a la red están jerarquizados entre sedes y secciones. Los primeros son solamente 3 y son entidades que ejercen un grado de influencia notable en su ámbito de actuación: la propia sede del Memorial Democràtic en Barcelona, el Consorci Memorial dels Espais de la Batalla de l'Ebre (COMEBE) y el Museu Memorial de l'Exili (MUME). Con respecto a los secciones, están a su vez jerarquizadas en centros de referencia y espacios, según su grado de desarrollo patrimonial.

A nivel temático, los espacios de memoria democrática de Cataluña están divididos en 4 grandes bloques: Segunda República, Guerra Civil, Frontera y exilio, y lucha antifranquista y recuperación democrática. Los espacios de la Segunda República son poco numerosos. Aunque por motivos políticos tal vez puedan representar un patrimonio incómodo y difícil de asumir para determinados sectores ${ }^{24}$, parece más adecuado achacar su poca presencia al hecho básico de que, tratándose de la época más lejana a nivel cronológico y anterior a la Guerra Civil, ha sido más difícil la pervivencia de sus vestigios patrimoniales. Los espacios de lucha antifranquista y recuperación democrática también son escasos y la gran mayoría se concentra en el radio urbano de Barcelona. Son los espacios de la Guerra Civil, así como los de frontera y exilio, los más numerosos y ricos en diversidad patrimonial e interpretativa. Sobre estos últimos, cabe reseñar además su potencial cohesionador a nivel transfronterizo, puesto que existen iniciativas patrimoniales, coordinadas desde ambos lados de la frontera pirenaica, que permiten el arraigo de un relato histórico y memorial común ${ }^{25}$.

\footnotetext{
territorio, un memorial en red en Cataluña", dirigido por Ricard Vinyes, El Estado y la memoria: Gobiernos y ciudadanos frente a los traumas de la historia (Barcelona: RBA Libros, 2009), pp. 569-608

${ }^{24}$ Maria Llombart, "Sobre memòries, el "Memorial Democratic" (2007-2011), ¿un projecte sense futur?", Tropelias: Revista de teoría de la literatura y literatura comparada, $\mathrm{n}^{\circ} 22$, (2014): pp. 58-69

${ }^{25}$ David González y Jordi Font, "La museización del patrimonio memorial transfronterizo: el caso del exilio republicano y sus espacios", MIDAS - Museus e estudos interdisciplinares, $\mathrm{n}^{\circ} 6,2016$ : pp. 1-17; y Jordi. Font; David. González; Gemma. Domènech y Salomó. Marquès, "La memoria del exilio republicano a través de sus espacios: patrimonio, turismo y museos en el territorio catalán transfronterizo", editado por I. Arrieta, Lugares de memoria traumática. Representaciones museográficas de conflictos políticos y armados (Bilbao: UPV/EHU Servicio Editorial, 2016), pp. 71-98.
} 


\section{TOPOGRAFÍA MEMORIAL DEL EXILIO REPUBLICANO}

El territorio catalán transfronterizo posee una rica y variada topografía de espacios de memoria del exilio republicano. En algunos de ellos hay iniciativas punteras a nivel cultural, con espacios patrimoniales consolidados en el territorio o incluso algún museo de referencia. En otras, de manera más modesta, existen marcadores e identificadores con cierto grado de interpretación. Todos estos lugares, en cualquier caso, dan forma a un territorio de memoria consolidado ${ }^{26}$, con presencia de episodios históricos de relevancia como la Guerra Civil española o la Segunda Guerra Mundial, cuya manifestación principal se da a través del exilio y sus diferentes ramificaciones históricas: retorno, resistencia y deportación.

En el contexto del proyecto "In Between?", cuya experiencia presentamos en el presente texto, el patrimonio posee un papel protagonista para el desarrollo del mismo. Será el conocimiento de los diferentes lugares patrimoniales relacionados con la memoria del exilio lo que posibilite un primer contacto con dicha memoria a los participantes del proyecto. El trabajo analítico desarrollado a lo largo de las diferentes visitas patrimoniales permitirá, con posterioridad, tener más herramientas para la elaboración de las entrevistas a los testimonios. El trabajo con los testimonios, sumado a la aportación patrimonial de los diferentes espacios de memoria trabajados, forjará la estructura sobre la que acabará construyéndose el resultado final del proyecto: un documental audiovisual sobre el exilio republicano y su memoria a ambos lados de la frontera.

Así pues, a continuación se presentarán los diferentes espacios de memoria del exilio republicano que han formado parte de la experiencia "In Between?", utilizando para ello una clasificación dentro del marco geográfico municipal.

\footnotetext{
${ }^{26}$ David González Vázquez, "El turismo de memoria y las implicaciones de la frontera: una aproximación teórica desde los Pirineos", editado por Ramon Arnabat y Montserrat Duch, Polítiques memorials, fronteres i turisme de memoria (Perpinyà-Tarragona: PUP-PURV, 2017), pp. 97-114.
} 


\section{En España}

\section{La Jonquera}

La Jonquera es un pequeño municipio de frontera, de poco más de 3.000 habitantes, cuya situación estratégica lo ha convertido en lugar de referencia para la historia y la memoria del exilio republicano. Así, en febrero de 2008, abre las puertas al público el Museo Memorial del Exilio - MUME, equipamiento que se convertiría desde entonces en el vector de desarrollo del patrimonio memorial del territorio. Su existencia en el municipio se justifica en que por La Jonquera, y en concreto por la que hoy día es la calle donde se ubica el museo, transitó aproximadamente la mitad del global de todos los exiliados del 39.

Aunque, además de la relación con la historia y la memoria del exilio, es verdaderamente interesante exponer también la evolución socioeconómica del municipio, de manera que pueda entenderse cómo un pueblo tan insignificante a nivel de población haya adquirido un papel referencial en el conjunto del patrimonio del exilio republicano.

Con la desaparición de las fronteras políticas entre países europeos, fruto de la consolidación del tratado de Schengen (1995), los municipios de frontera tuvieron que afrontar un dificultoso proceso de reconversión de su tejido económico, y, por tanto, social y cultural. La Jonquera había vivido históricamente por y para la frontera, con el grueso de su actividad económica basculando siempre sobre el impacto de las fuerzas de seguridad, las estructuras aduaneras, o en un ámbito más informal, el contrabando. En la actualidad, aun manteniendo una relativa presencia de fuerzas de seguridad relacionadas con el control fronterizo, la nueva situación de posfrontera ha derivado el modelo económico del municipio hacia el sector servicios. Dicho modelo, sin embargo, sigue fuertemente influenciado por la situación liminar del pueblo, ya que aún sin la existencia de aduanas, persisten diferencias substanciales a nivel legislativo e impositivo entre los estados español y francés. De esta manera, los grandes almacenes donde el alcohol y el tabaco ejercen de principal reclamo, decenas de gasolineras, y también numerosos prostíbulos conforman la base de la economía de La Jonquera en el siglo XXI. La legislación más permisiva con respecto a la prostitución, y unos impuestos menores en alcohol y tabaco atraen a los consumidores franceses a cruzar la frontera. 
Es importante tener en cuenta este contexto socioeconómico de posfrontera para entender el valor del patrimonio memorial ligado al territorio. Así, el exilio republicano, sus espacios y sus diferentes manifestaciones patrimoniales de carácter material e inmaterial, son fuente de inspiración para dotar a tan singular municipio de los recursos culturales necesarios para revertir la peculiar imagen del municipio. Es así como aparece la posibilidad de dar forma a un proyecto cultural que pueda, a la vez, mejorar la imagen del pueblo y ejercer como foco de atracción de turismo cultural ${ }^{27}$. La idea de poner en valor el patrimonio del exilio republicano se impuso a otras propuestas, como el contrabando o el parque natural de la Albera, y esto fue así puesto que era una temática estrechamente ligada al territorio y a su historia local, pero también con una notable proyección internacional.

Es así como el ayuntamiento de La Jonquera dio comienzo al proyecto de museo que, a través de los fondos estructurales FEDER INTERREG II-A y en asociación con el ayuntamiento de Argelès-sur-Mer, contaría con la implicación de la UE. La Generalitat de Cataluña a través de los diversos departamentos competentes según la época, y la diputación de Girona también se implicaron en el proyecto. El proceso se inicia el año 2001. Los proyectos museológico y museográfico fueron responsabilidad de los historiadores Jaume Santaló y Enric Pujol ${ }^{28}$, mientras que el proyecto arquitectónico fue desarrollado por Rafael Cáceres y Philippe Pous. De la unión de un antiguo local municipal y alguna casa colindante surgió el espacio que albergaría al MUME, cuya disposición quedaría distribuida en planta baja, primera y segunda planta. En la planta baja se ubicarían la recepción, la tienda, el aula pedagógica y la sala polivalente de exposiciones temporales, además del vestíbulo y los servicios. La primera albergaría las oficinas y tres salas de la exposición permanente, mientras que en la segunda se ubicarían la sala de maquinaria y otras dos salas de la exposición permanente. La exposición permanente, pues, se divide en 5 espacios, presentados en este orden de visita: Consideración general del exilio; Guerra, derrota y retirada; la diáspora; la vivencia del exilio; y el legado del exilio.

\footnotetext{
27 Enric Pujol, Projectes culturals transfronterers..., op.cit., pp. 74-84; y Jordi Font, "A cavall de la història i la memòria: el Museu Memorial de l'Exili de la Jonquera-MUME", Mnemosine: revista catalana de museologia, $\mathrm{n}^{\circ} 5$ (2009): pp. 105-113.

28 Enric Pujol, “El Museu de l'Exili de La Jonquera”, Mnemosine: revista catalana de museologia, $\mathrm{n}^{\mathrm{0}} 1$, (2003): pp. 67-78.
} 


\section{Imagen $n^{0}$ 1. MUME (La Jonquera). Vista exterior}

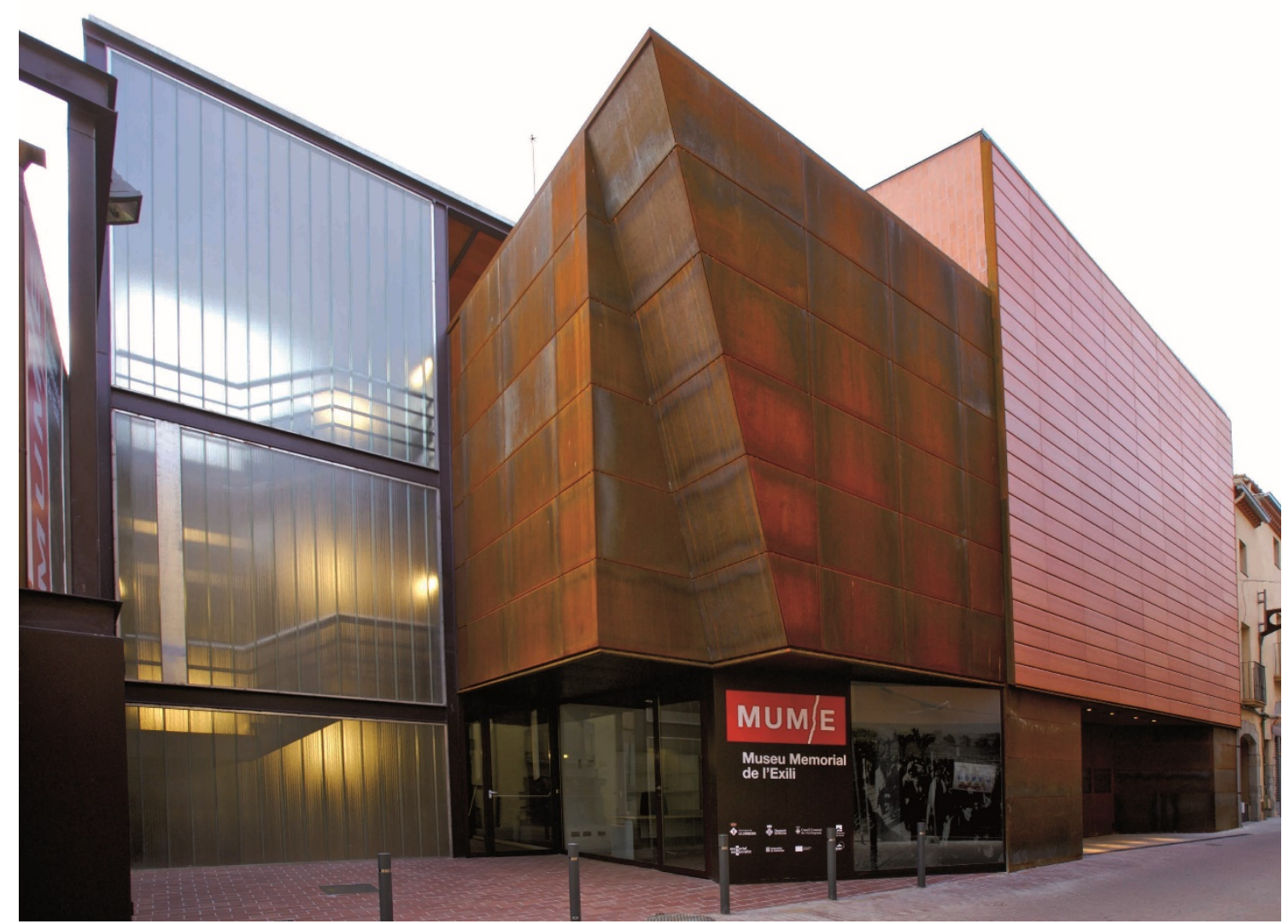

Fuente: MUME

\section{Agullana}

La población ampurdanesa de Agullana es, probablemente, una de las más influenciadas por la huella del exilio republicano y su memoria. Es conocida como "la última capital de la República", ya que algunos de los organismos oficiales republicanos más representativos se emplazaron en distintos lugares de esta localidad antes de partir al exilio.

En las escuelas se instaló el Ministerio de Estado y el ministro Álvarez del Vayo, y en Can Bech de Baix lo hizo el Estado Mayor del Ejército Republicano, utilizando Can Perellada como residencia de sus miembros, incluyendo al general Vicente Rojo. Representantes de las embajadas de la URSS y de México se albergaron en dos casas del pueblo, mientras que el presidente del Gobierno, Juan Negrín, se hospedó en Can Bech de Dalt, una masía en las afueras del pueblo. La Generalitat de Cataluña, por su 
cuenta, ubicó la comitiva del presidente Companys, la sede del 'Institut d'Estudis Catalans" y un gran número de intelectuales del país (como Mercè Rodoreda o Pompeu Fabra), en el Mas Perxés ${ }^{29}$.

A raíz de esta relación con el exilio intelectual de Cataluña, Agullana dispone actualmente del Centro de Interpretación del Exilio Cultural Catalán de 1939, un lugar que «propone un recorrido por el conjunto de las letras, el pensamiento y las ciencias catalanas en la difícil disyuntiva del exilio» ${ }^{30}$. Juntamente con la apertura de este pequeño museo, Agullana ha señalizado aquellos espacios más representativos del exilio en la localidad (además de los lugares ya mencionados, también otros casos, como la "Societat la Concòrdia" o Can Bach (actual ayuntamiento) donde hubo un hospital de campaña y un arsenal, respectivamente.

\section{Imagen no 2. Centro de Interpretación del Exilio Cultural Catalán de 1939 (Agullana). Detalle interior}

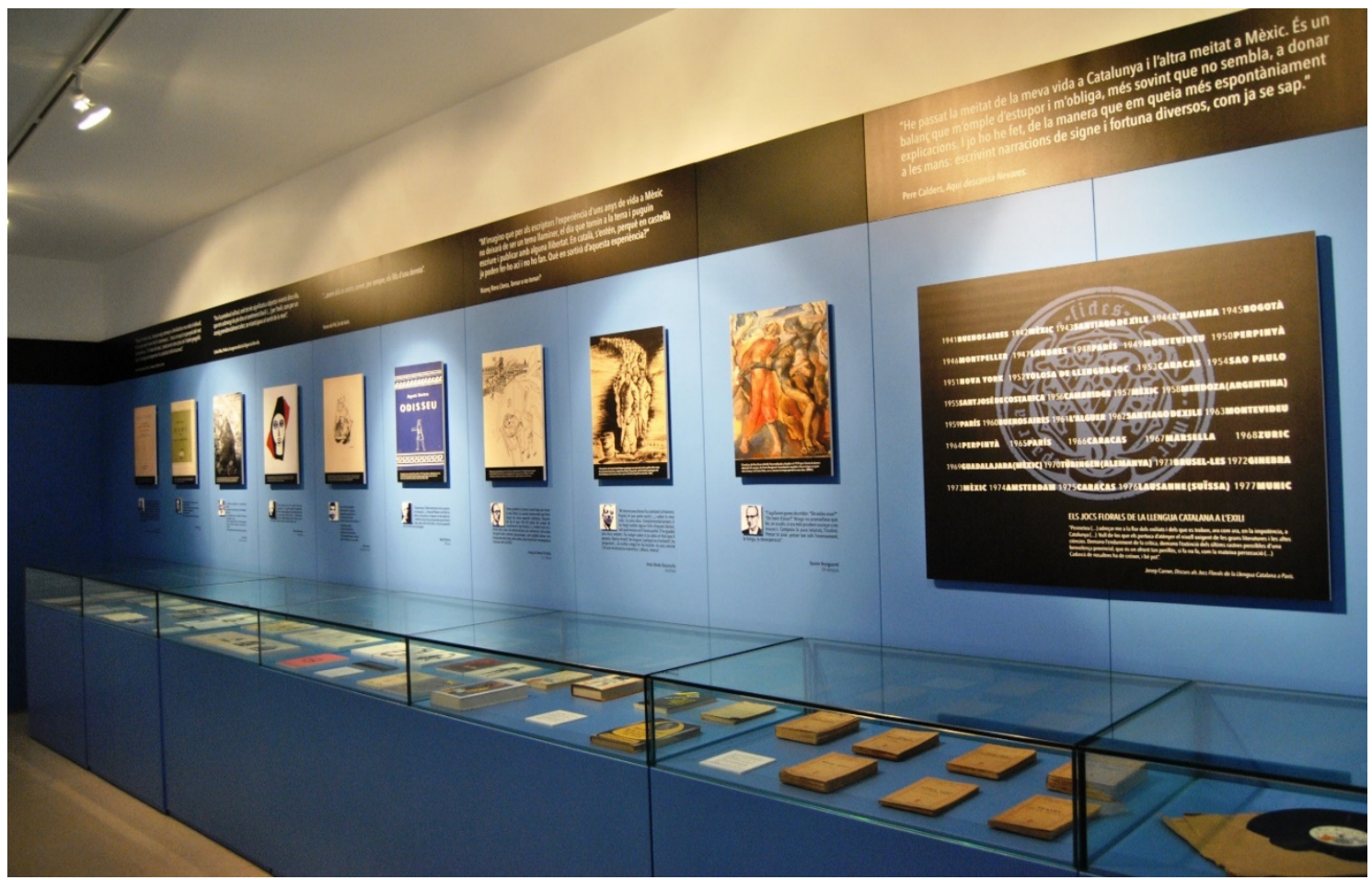

Fuente: MUME

\footnotetext{
${ }^{29}$ Miquel Serrano. "El mas Perxés d'Agullana, espai de memòria de la retirada". Annals de l'Institut d'Estudis Empordanesos, nº41, (2010): 51-75.

${ }^{30}$ David González y Jordi Font, "La museización del patrimonio memorial transfronterizo: el caso del exilio republicano y sus espacios", MIDAS - Museus e estudos interdisciplinares, $\mathrm{n}^{\circ} 6,2016$ : p.9
} 


\section{La Vajol}

El pequeño pueblo de La Vajol se encuentra a tocar de la frontera con Francia. Debido a esta particularidad también tiene una interesante vinculación con la historia y la memoria del exilio republicano. En La Vajol encontramos diversas manifestaciones patrimoniales que nos remeten a aquellos días.

Una de las más representativas es el Monumento al Exilio, ubicado cerca del aparcamiento municipal. El monumento consta de una escultura de bronce de Joan García y Lola Reyes, erigida en 1999. Fue levantada por suscripción popular y a iniciativa de algunas entidades memorialistas. Representan la figura de Mariano Gracia y su hija Alicia Gracia Bamala, camino del exilio por el Coll d'Ares. La escultura está inspirada en una imagen real, inmortalizada por el fotógrafo francés Roger Violet y publicada en la prestigiosa revista francesa "L'Illustration". Desde que se publicó esta fotografía, esta imagen se convirtió en una de las más emblemáticas del exilio republicano.

Encontramos también distintas placas memoriales instaladas por agrupaciones o partidos políticos en la entrada del pueblo, cerca del monumento al minero. Allí es donde se considera que empezó el camino del exilio. También está señalizado el Coll del Lli, el punto fronterizo con Francia, para recordarnos que por aquí pasaron las personalidades políticas más relevantes: Companys, Azaña o el lehendakari Aguirre, entre muchas otras.

En el Mas de Can Barris se alojó el presidente de la República, Manuel Azaña, muy cerca del que, sin duda, es el vestigio patrimonial que esconde una de las historias más sugerentes de toda aquella época: la Mina Canta. Se trata de una mina propiedad entonces de la familia Canta (hoy propiedad municipal), de donde se extraía filosilicato de magnesio hidratado, material del que sale el talco. Debido a su inmejorable posición geográfica, al lado de la frontera, la mina sirvió de escondite para "el tesoro de la República”. A partir de mediados de 1937, se resguardaron en este lugar obras de arte, lingotes, joyas y otras posesiones valiosas propiedad del gobierno republicano con un valor estimado superior a los 200 millones de dólares ${ }^{31}$. Una impresionante labor

\footnotetext{
${ }^{31}$ Alfons Martínez Puig "La postguerra del Patrimoni Artístic a l'Alt Empordà febrer-setembre 1939”, Annals de l'Institut d'Estudis Empordanesos, nº 45, 2014: pp. 143-174.
} 
logística convirtió este remoto lugar en un escondite seguro desde donde saldrían hacia el exilio la mayoría de los materiales ahí resguardados. El toque de aventura aportado por la historia del tesoro, juntamente con el potencial didáctico relativo al relato de la salvaguarda de las obras de arte y la monumentalidad del edificio, aún presente, hacen de la Mina Canta un lugar espectacular con muchas posibilidades de actuación patrimonial $^{32}$.

\section{Imagen $n^{0}$ 3. Edificio operativo de la Mina Canta (La Vajol). Vista exterior}

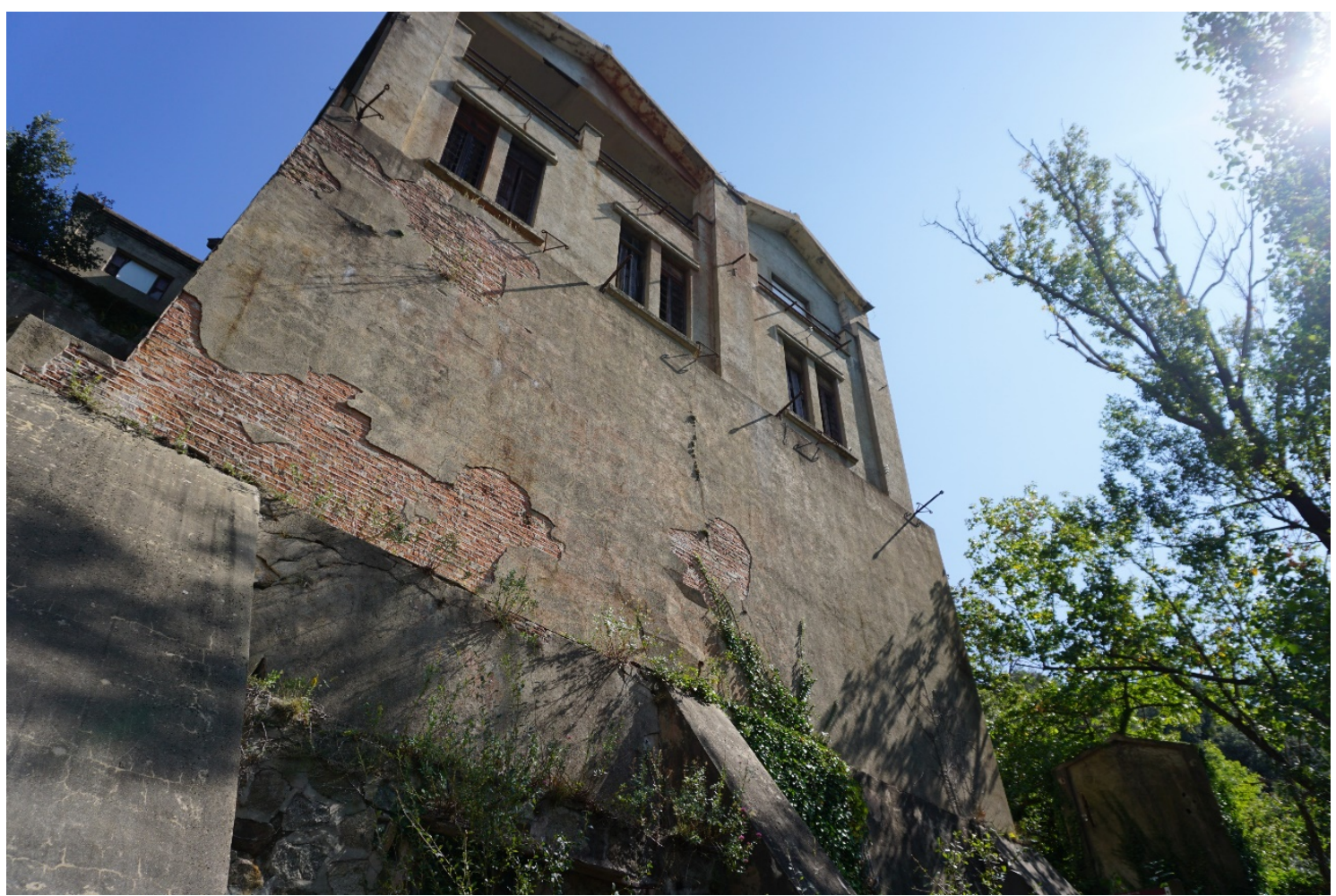

Fuente: Archivo “In Between?" - ENRS

\section{Portbou}

El pueblo de Portbou es el último municipio de la costa mediterránea española antes de llegar a la frontera francesa. Igual que su homónimo francés, Cerbère, Portbou nació como municipio en el siglo XIX fruto de las necesidades del entramado ferroviario de la frontera. A raíz de las diferentes anchuras de vía entre España y

\footnotetext{
${ }^{32}$ Ferran Riera Miralles, "Valorització patrimonial de la mina Canta de La Vajol mitjançant una proposta aplicada de turisme cultural” (TFM, UdG, 2016), http://hdl.handle.net/10256/13895
} 
Francia, fueron necesarias infraestructuras ferroviarias como las que se crearon en Portbou y Cerbère y, con ellas, poblaciones que pudieran darles cobertura.

El paso fronterizo entre Portbou y Cerbère fue el segundo más utilizado durante "la Retirada", después del de la Jonquera y le Perthus. El recorrido transcurría por la carretera que une los dos municipios y los dos estados, el español y el francés: el Coll dels Belitres. En este punto fronterizo se inauguró en 2009 el Memorial del Exilio del Coll dels Belitres, fruto de la colaboración entre el Memorial Democràtic, el Ayuntamiento de Portbou y el MUME.

En Portbou no sólo existe patrimonio memorial referente al exilio, sino que, debido a la doble dirección fronteriza, se puede hablar también de los evadidos de la Segunda Guerra Mundial. Se trataba de aquellas personas que huían del nazismo y emprendían el camino al sur de los Prineos ${ }^{33}$. Entre aquellos, destaca la figura del filósofo judeo-alemán Walter Benjamin, quien consiguió llegar a Portbou con la intención de seguir el camino hasta Lisboa y finalmente llegar a Nueva York. Al ser detenido por las autoridades españolas, y obligado a retornar al territorio ocupado por los nazis, decidió suicidarse, acabando sus días en Portbou. Además de una ruta señalizada por el pueblo, el elemento más significativo con relación a su memoria es el Monumento "Pasajes", creado por el artista israelí Dani Karavan e inaugurado en 1994. La intervención artística, que juega con las posibilidades y ausencias del terreno, se encuentra a las afueras del cementerio municipal, donde descansan los restos del filósofo dentro de una fosa común.

\section{Imagen $n^{\circ}$ 4. Pasajes - Memorial a Walter Benjamin realizado por Dani Karavan (Portbou). Detalle exterior}

\footnotetext{
33 Josep Calvet, Les muntanyes de la llibertat. El pas d'evadits pels Pirineus durant la Segona Guerra Mundial 1939-1944. (Barcelona: L’Avenç, 2008)
} 


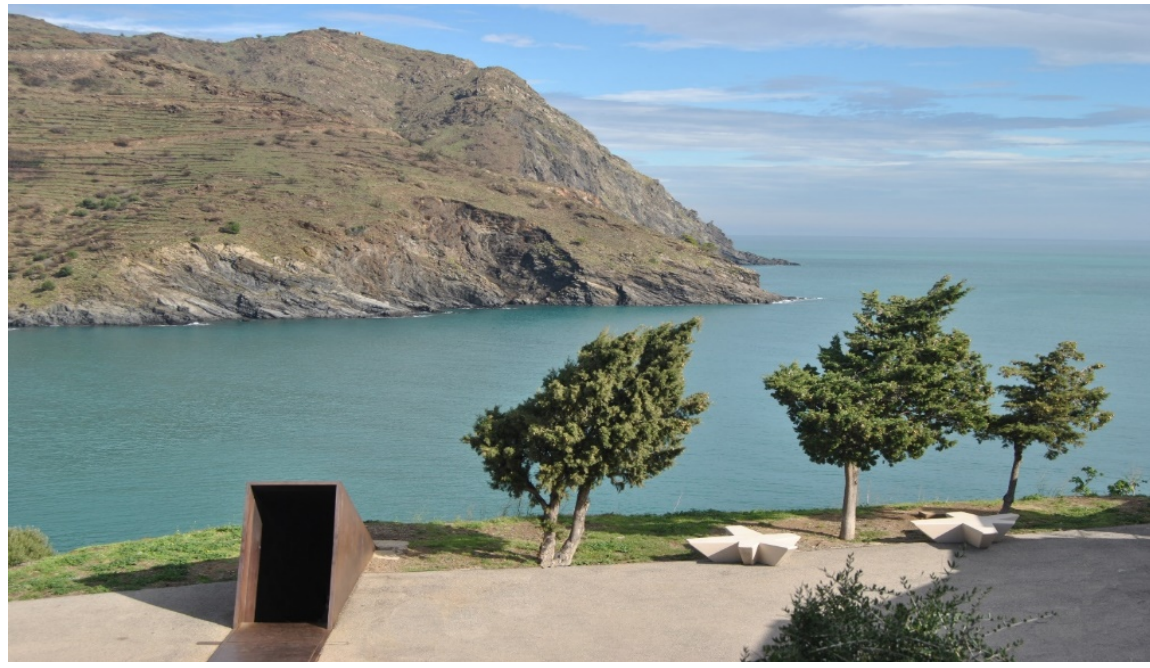

Fuente: MUME.

\section{Al norte de los Pirineos}

\section{Las Illas}

Se trata de la primera localidad en territorio francés que se encuentra siguiendo el camino del Coll del Lli. Por lo tanto, es el primer lugar que encontraron los exiliados que siguieron por esa ruta, como Companys, Azaña o Negrín. Todavía existe el Hostal Trabucaires, donde hay una placa que rememora aquel paso. Al otro lado del pueblo, cerca de la parada del bus, se encuentra el monumento a la Segunda República.

\section{Imagen $n^{0}$ 5. Monumento a la Segunda República (Las Illas). Vista}

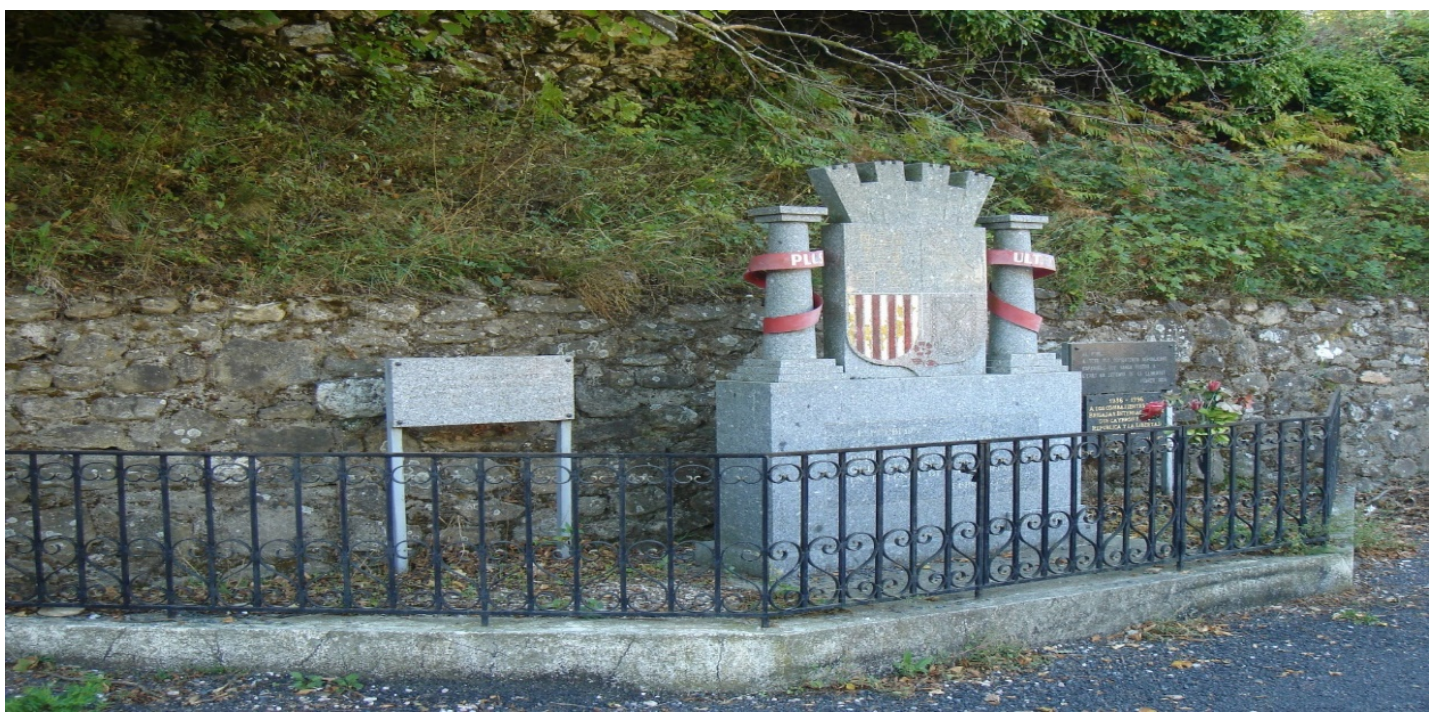

Fuente: MUME 


\section{Argelès-sur-Mer}

Argelès-sur-Mer es, probablemente, el lugar de memoria traumática más imponente de toda "la Retirada". En el imaginario colectivo se ha consolidado como el paradigma de la humillación, de la derrota y del desespero de aquellos centenares de miles de personas que huyeron de un infierno para ir a parar, en muchos de los casos, a uno peor. En la playa de Argelès-sur-Mer se encuentra el campo de concentración donde la densidad fue más pronunciada y donde el nivel de improvisación en su creación fue total $^{34}$. Inaugurado a inicios de febrero de 1939, llegó a tener 100.000 internos durante las primeras semanas. Posteriormente, el número se reduciría a unos cuantos miles y se construirían los barracones y servicios que no existían al principio, donde la arena, el agua del mar y las alambradas era todo lo que ofrecía el campo. Fue cerrado en 1941.

El actual espacio donde antes había el campo está ocupado por la propia playa, así como viviendas de uso turístico, como casas, campings y algún hotel. Es un lugar turístico donde encontramos únicamente una placa informativa y un monolito conmemorativo donde estuvo la entrada del campo. También está el lugar conocido como "el cementerio de los españoles", donde una estela memorial recuerda los 147 adultos y un árbol los 70 niños y niñas que, de forma oficial, constan como muertos en el campo.

En 2014 se inauguró el Mémorial du Camp d'Argelès, gestionado por el Ayuntamiento y la asociación FFREEE (Fils et Filles de Republicaines Espagnols et Enfants de l'Exode), Funciona como un centro de interpretación centrado en las

\footnotetext{
${ }^{34}$ Utilizaremos la expresión "campo de concentración" para referirnos también a los denominados "campos de internamiento", o sea, aquellos campos donde los republicanos españoles fueron aprisionados durante la Retirada. El nombre de "campo de internamiento" es el más utilizado por la historiografía francesa, y autores como Denis Peschansky lo justifican diciendo que los campos de internamiento del sur de Francia implicaban una situación coyuntural, no ideológica, y que eran algo transitorio. A diferencia de ellos, según Peschansky, un campo de concentración estaba relacionado con un sistema estructural ideológico, y eso no se daba en la Francia de los campos de internamiento entre los años 1939 y 1946. Esta visión no es compartida por gran parte de las asociaciones de descendientes, así como también es discutida desde la historiografía al sur de los Pirineos. El argumento principal es el hecho que, en la primera época de los campos, los organismos oficiales franceses utilizaban en todas sus comunicaciones el nombre de "campos de concentración", cosa que también hacía toda la prensa del país. Sin ir más lejos, en la propia entrada del campo de Saint-Cyprien, se podía leer "Camp de concentration. Vive la France". Sería con el paso del tiempo que el nombre de "campo de internamiento" se iría imponiendo en Francia, tal vez para disociar sus campos de los campos de concentración de la Alemania nazi. Ver Josep Clara, "Camps de reclusió, camps de concentración", dirigido por Pelai Pagés, L'exili republicà als Països Catalans. Una diàspora històrica (Barcelona: Ed. Base, 2015) pp: 109-136; y Denis Peschansky, La France des camps. L'internement, 1938-1946 (París: Gallimard, 2002).
} 
particularidades de la vida en el campo, como la vigilancia, la higiene, los barracones o la vida cultural, entre otras. En 2017 fue reubicado, desde su primer emplazamiento al Chateau Valmy, un lugar céntrico de la localidad.

\section{Imagen $n^{0}$ 6. Monolito en memoria de los republicanos españoles internados en el campo de Argelès-sur-Mer (Plage des Pins - Argelès-sur-Mer). Vista}

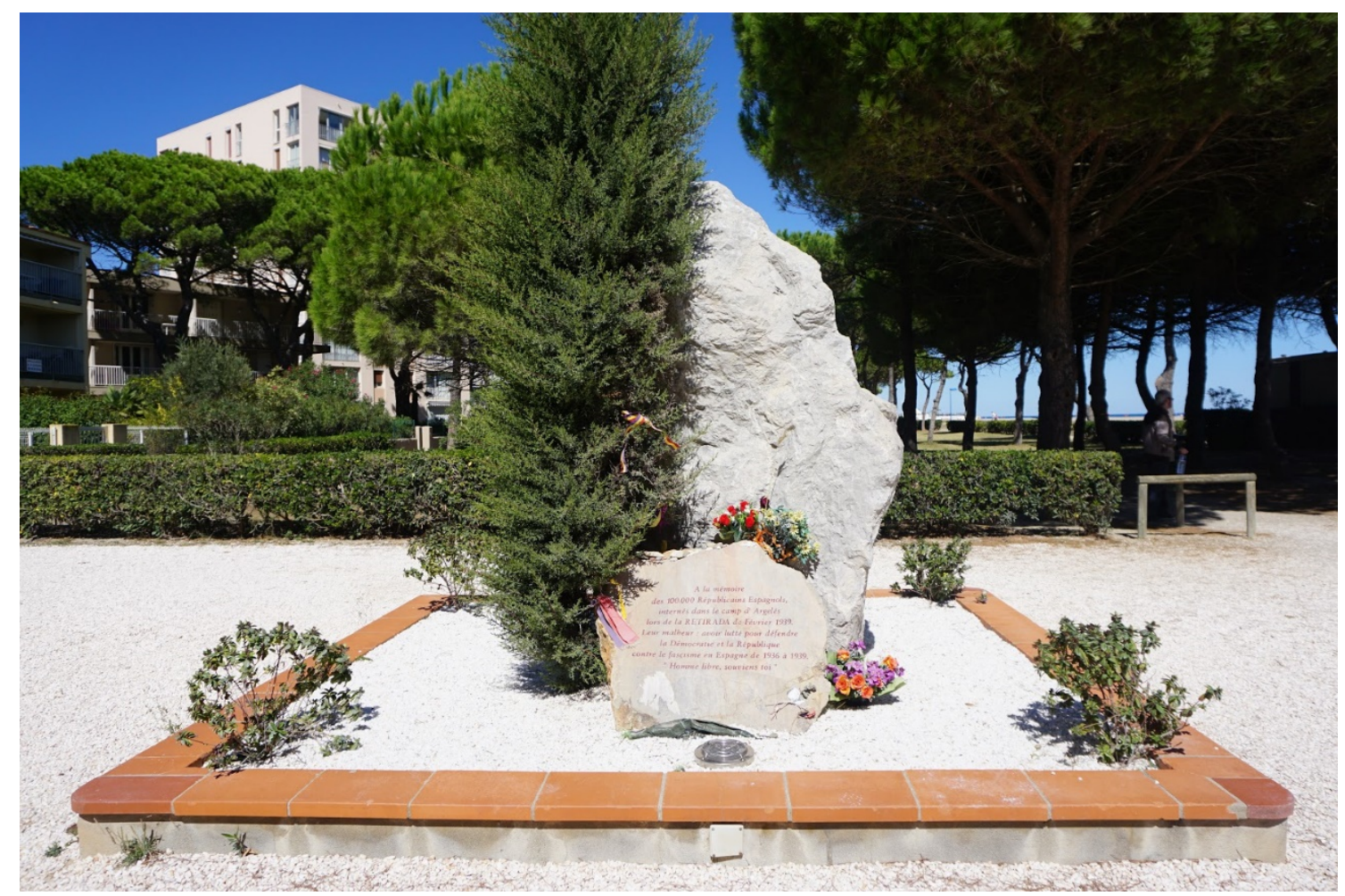

Fuente: Archivo “In Between?" - ENRS.

\section{Saint-Cyprien}

Limitando con la parte norte de Argelès-sur-Mer, se encuentra la villa de SaintCyprien, en cuya playa también existió un campo de concentración. Construido con un poco más de previsión, también acogió, igual que Argelès-sur-Mer, a un número muy elevado de refugiados en sus primeras semanas de funcionamiento, cerca de 80.000. Por otro lado, debe tenerse en cuenta que era un campo de dimensiones mayores y había 
mejores condiciones de vida, sobre todo al inicio. Fue construido poco después que el de Argelès-sur-Mer y cerrado también en 1941, en el mes de octubre.

La playa de Saint-Cyprien es un lugar muy turístico. Actualmente, dispone de bloques de apartamentos de dimensiones considerables, hoteles, comercios y servicios de restauración. La principal referencia al exilio, que no al campo, la encontramos cerca de la playa, donde se levanta el monumento a Lluís Companys. Se trata de una pieza interesante desde el punto de vista memorial pues, más allá de la historia genérica del exilio, este lugar tiene poco que ver con la figura de Companys, ya que nunca pisó Saint-Cyprien y mucho menos su campo. También llama la atención que se trate de un monumento erigido en 1974, una fecha absolutamente avanzada a cualquier iniciativa de recuperación memorial del exilio, tanto en Francia como en España, donde aún perduraba la dictadura franquista. Si bien es cierto que la placa hace referencia no sólo a Companys, sino a todos los catalanes muertos en defensa de la libertad enrolados en el ejército francés, el hecho de destacar su figura es suficientemente sintomático de su relevancia a los dos lados de la frontera pirenaica. El monumento es obra del escultor Miquel Paredes y fue encargada por el entonces alcalde de Saint-Cyprien, Joan Olibó, histórico militante socialista y antiguo resistente.

En la otra punta del emplazamiento del campo de Saint-Cyprien hay también un monumento erigido a las personas que murieron ahí, y en el cementerio del pueblo encontramos una placa conmemorativa del antiguo cementerio de los españoles.

\section{Imagen $n^{0}$ 7. Monumento a Companys y a los caídos catalanes (Saint Cyprien Plage). Vista}




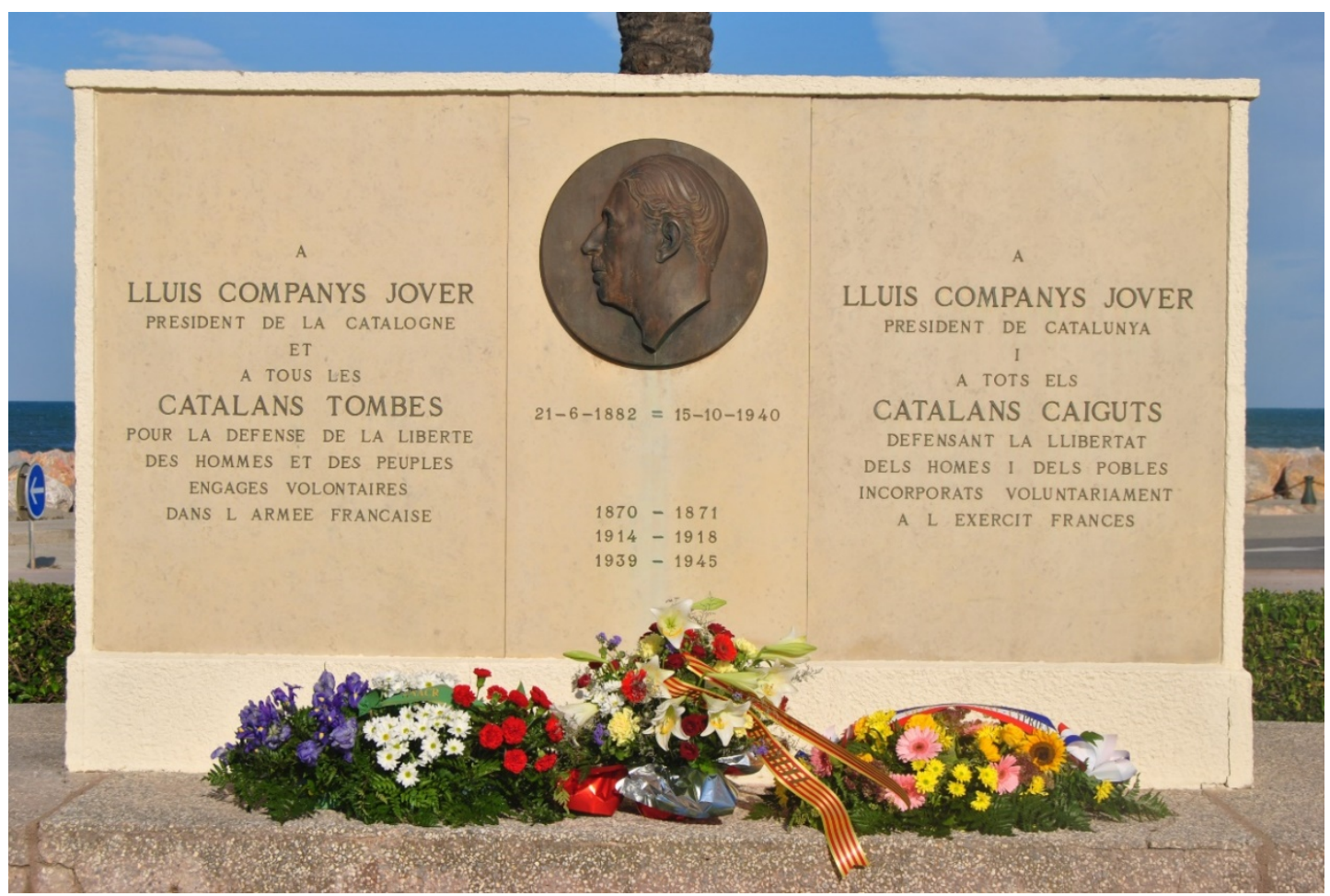

Fuente: MUME.

\section{EIne}

Como contrapunto a las dramáticas historias vividas en los campos de concentración, encontramos la historia de la Maternidad de Elne. En este pueblo agrícola existió, entre noviembre de 1939 y mayo de 1944, un lugar donde las mujeres embarazadas recluidas en los campos podían dar a luz a sus criaturas con condiciones $\operatorname{dignas}^{35}$.

Elizabeth Eidenbenz, una joven maestra suiza que pertenecía a la Sociedad Civil Internacional, fue la encargada de dirigir este proyecto a través de la organización “Ayuda suiza a los niños de España” y posteriormente de la Cruz Roja Internacional. La maternidad se instaló en el "Chateau d'en Bardou", un palacete burgués en las afueras de la localidad. Casi seiscientas ${ }^{36}$ criaturas fueron traídas al mundo dentro de la

\footnotetext{
${ }^{35}$ Tristan Castaner, Femmes en exil, mères des camps. Élisabeth Eidenbenz et la maternité suisse d'Elne (1939-1944). (Perpinyà: Éditions Trabucaire, 2008).
}

${ }^{36}$ Algunas fuentes hablan de 595 y otras de 597. 
Maternidad de Elna. Las madres eran aproximadamente cuatrocientas mujeres españolas y doscientas mujeres judías y gitanas víctimas de la persecución nazi.

Tras la Segunda Guerra Mundial, la historia de la Maternidad permaneció olvidada absolutamente para todo el mundo. Varias décadas después, debido a la acción de uno de los niños judíos ahí nacido, Guy Eckstein, y del propietario que restauró el edificio en los años noventa, François Charpentier, la memoria de la maternidad salió a la luz. Elizabeth Eidenbenz, por aquel entonces aún con vida, recibió varios reconocimientos por su labor: Justa entre las naciones en 2002 (Israel), Cruz de Oro del Orden Civil y la Solidaridad Social (España) y Cruz de Sant Jordi (Cataluña) en 2006, y la Legión de Honor (Francia) en 2007.

El Ayuntamiento de Elne liderado por Nicolás García ${ }^{37}$, alcalde descendiente del exilio, gestionó a partir del 2004 la adquisición del edificio y su progresiva adaptación como espacio museístico. Hoy en día es un espacio consolidado que recibe de manera regular más de 25.000 visitantes anuales y que la propia Elizabeth Eidenbenz, fallecida en 2011, ayudó a consolidar con su archivo personal.

\section{Imagen $n^{0}$ 8. Maternidad de Elne (EIne). Vista exterior}

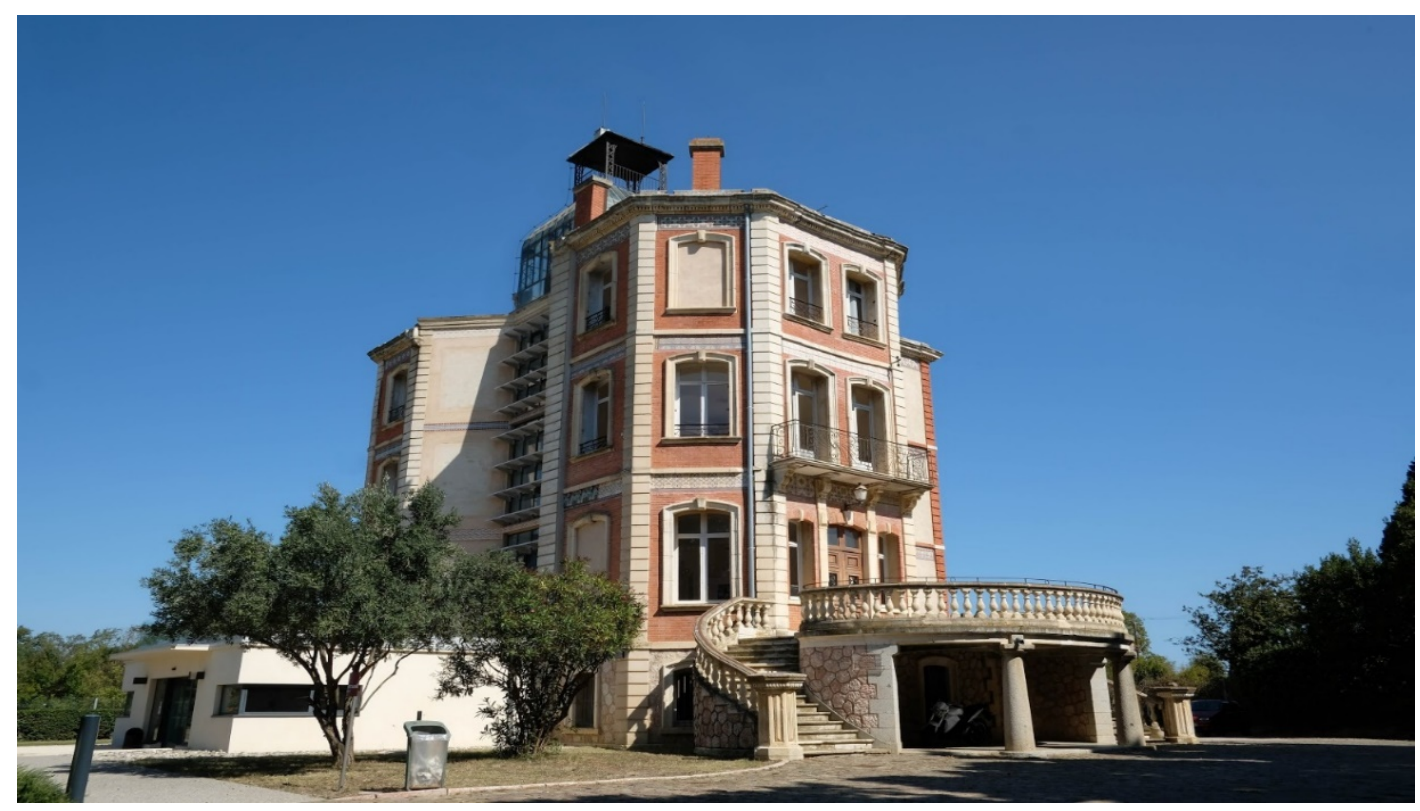

Fuente: Archivo “In Between?”- ENRS.

\footnotetext{
${ }^{37}$ Nicolás García es uno de los ocho testimonios que participan en el documental.
} 


\section{Collioure}

Esta pequeña localidad con enorme encanto, clásico pueblo de pescadores que se ha convertido en un recurrente destino turístico, dispone de elementos patrimoniales de gran valor vinculados a "la Retirada". Por aquí pasaron muchos de aquellos refugiados que venían siguiendo la ruta costera desde el paso de frontera del Coll dels Belitres, entre Portbou y Cerbère.

El propio castillo de Collioure, conocido como "Chateau Royal", esconde una de las historias más duras, vergonzantes y poco conocidas de "la Retirada" en suelo francés. Allí funcionó un campo muy concreto, denominado por las autoridades francesas como Centro de Reagrupamiento Especial o Campo Especial, por donde pasaron aquellos refugiados considerados extremistas o peligrosos. Es decir, se trataba de un campo disciplinario donde los exiliados españoles iban a parar como castigo. $\mathrm{Su}$ existencia no estuvo exenta de polémicas y secretismo, y gracias a la presión de la izquierda francesa se pudo finalmente desmantelar. Se calcula que durante el tiempo que estuvo en funcionamiento, entre marzo y diciembre de 1939, pasaron cerca de un millar de personas ${ }^{38}$.

La historia que sí es ampliamente conocida es la del poeta Antonio Machado. Huido a través de Portbou, llegó con parte de su familia a Collioure el 28 de enero de 1939 y se alojaron en el Hostal Quintana, hoy en día una casa particular. Su delicado estado de salud no le permitió vivir más allá del 22 de febrero, cuando murió, y Collioure presenció un multitudinario entierro donde pudieron asistir algunos militares republicanos confinados en el Château Royal. La tumba definitiva del poeta no acabó de instalarse hasta el año $1958^{39}$, donde también descansan los restos de su madre Ana Ruiz, fallecida tres días después del poeta. La calle que lleva del Hostal Quintana al cementerio se llama Rue d'Antonio Machado, y su tumba es un auténtico lugar de peregrinación y de homenaje a los ideales republicanos. A raíz de los diferentes escritos que los visitantes solían dejar en su tumba como ofrenda al poeta, la Fundación Antonio Machado de Collioure instaló un buzón a su lado en los años 1980. Toda la

\footnotetext{
${ }^{38}$ Gregory Tuban. Les séquestrés de Collioure. Un camp disciplinaire au Chateau Royal en 1939. (Perpignan: Editions Mare Nostrum, 2003)

${ }^{39}$ Financiada mediante subscripción popular, a iniciativa de Pau Casals en 1957.
} 
documentación recogida desde entonces ha conformado el núcleo del archivo "Palabras en el tiempo", que se conserva en la fundación ${ }^{40}$.

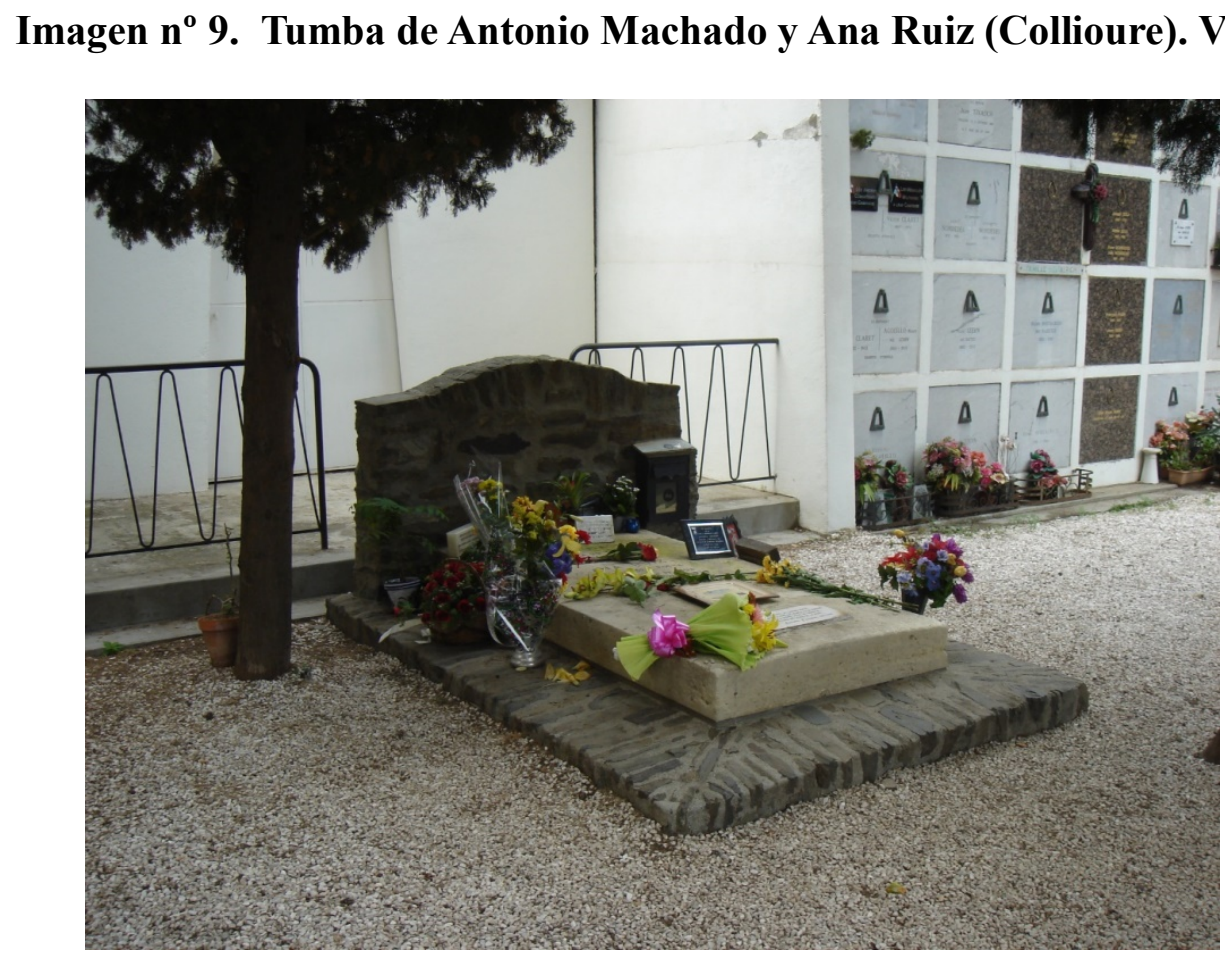

Fuente: MUME.

\section{Rivesaltes}

A las afueras del pueblo de Rivesaltes, tocando a Perpignan, se encuentran aún hoy en día algunos de los restos materiales de la época de los campos de internamiento al sur de Francia.

El campo de Rivesaltes fue ideado por la Francia de Vichy que, aprovechando la infraestructura existente en el antiguo campo de instrucción militar "Camp Joffre", fue inaugurado como campo de reclusión en 1941. A diferencia del resto de campos de alrededor, surgidos a raíz de "la Retirada" y de la improvisación, este será un campo con vocación de centralizar el sistema de internamiento y de liberar el territorio del resto de campos. Muy pronto entró en la dinámica de la reclusión y la deportación de la Segunda

\footnotetext{
${ }^{40}$ Veronica Sierra Blas, "El diálogo que nunca cesa: el archivo de los lectores/as de Antonio Machado en Collioure" (conferencia presentada en el $80^{\circ}$ Aniversario de la muerte de Antonio Machado, Collioure, 24/02/2019) http://www.machado-collioure.fr/wp-content/uploads/2019/02/VSB-CONFERENCIAHOMENAJE-FAM-2019.pdf
} 
Guerra Mundial, ya que una vez los nazis ocuparon el sur de Francia se convertiría en un campo de tránsito. Es decir, allí se concentraría y clasificaría a la población que más tarde sería deportada a los campos de exterminio del este de Europa, judíos y gitanos mayoritariamente. Posteriormente, tuvo muchos más usos: campo de prisioneros nazis durante la postguerra, campo de acogida de harkis argelinos ${ }^{41}$ después de la guerra de Argelia, o incluso centro de retención administrativo entre finales de los años ochenta y 2007.

En octubre de 2015 se inauguró el Mémorial de Rivesaltes. Se trata de un espectacular museo con un edificio de nueva planta de 4.000 metros cuadrados donde, a través de una museografía de última generación con predominio audiovisual, el visitante puede hacer un recorrido histórico desde los tiempos de la Guerra Civil española hasta casi la actualidad, con el tratamiento de episodios relativos a los refugiados de todo el mundo. La visita se complementa con un circuito exterior en el que pueden contemplarse los restos de alguno de los barracones del campo.

\section{Imagen $n^{0}$ 10. Vestigio exterior del Campo de Rivesaltes (Rivesaltes). Vista}

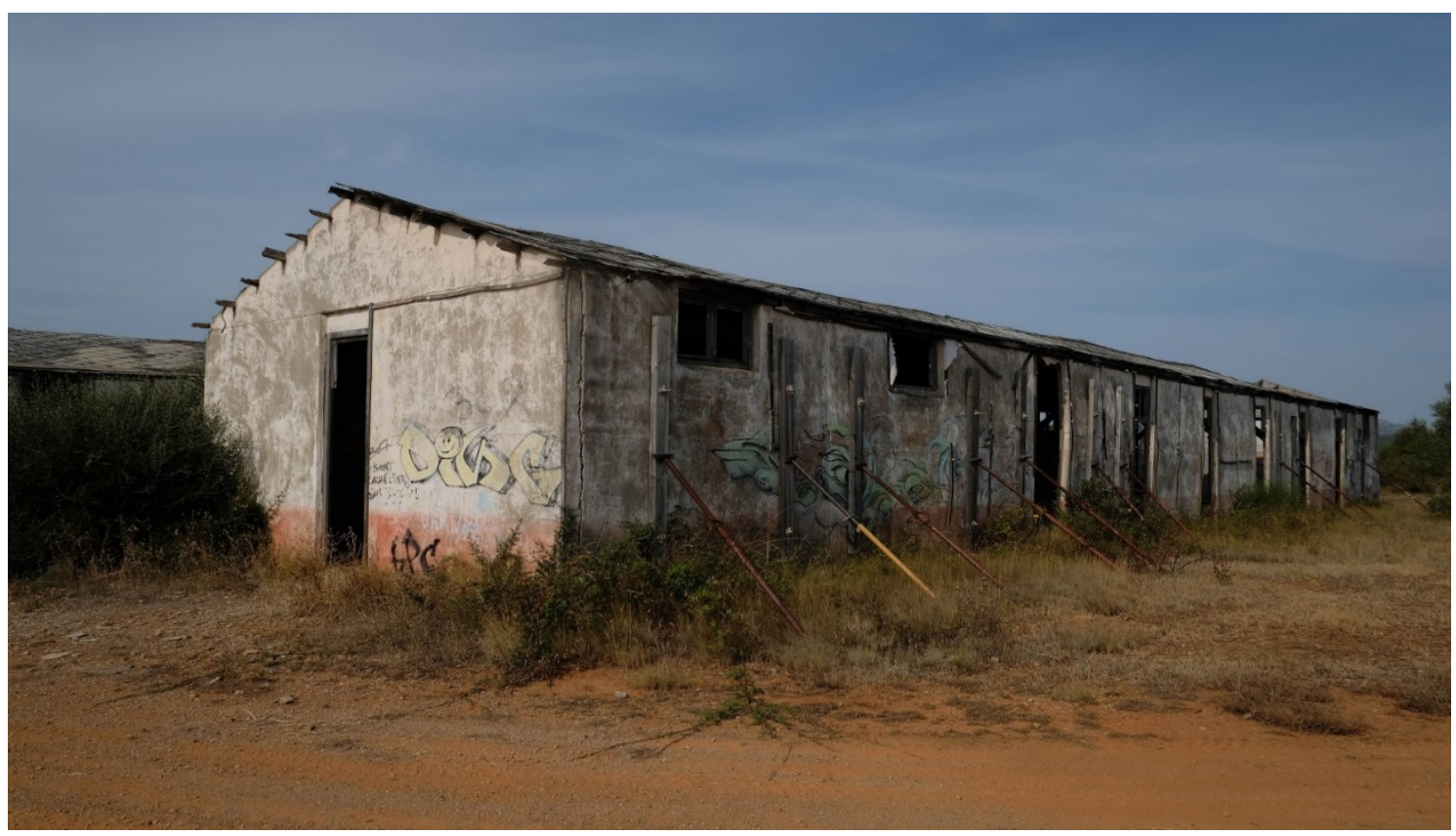

Fuente: Archivo “In Between?”- ENRS.

\footnotetext{
41 Argelinos musulmanes que combatieron al lado del ejército francés durante la Guerra de la independencia de Argelia.
} 


\section{EL PROYECTO "IN BETWEEN?":}

El proyecto "In Between?" 42 es una iniciativa promovida y dirigida por el ENRS (European Network Remembrance and Solidarity), una entidad con sede en Polonia cuya misión pasa por fomentar el conocimiento y el diálogo intercultural sobre el pasado reciente de Europa. Se trata de un proyecto educativo, del cual pueden participar estudiantes de todo el continente, donde se desarrollan capacidades de acción e investigación interdisciplinaria en el campo audiovisual, archivístico y narrativo.

La primera edición tuvo lugar en abril del año 2016, y desde entonces se han ido replicando anualmente hasta la actualidad. Algunos años, incluso, se han celebrado de manera semestral ${ }^{43}$. Hasta el presente, pues, se ha trabajado sobre la frontera en lugares tan diversos como dispersos dentro del marco geográfico europeo. Así, a lo largo de las sucesivas ediciones, además de la región transfronteriza catalana, se trabajaron las siguientes zonas de frontera: Vukovina (Rumanía - Ucrania); la región Lubuskie (Polonia - Alemania); la región Banska Bystrica (Eslovaquia - Hungría); Transylvania (Rumanía); la zona fronteriza entre Chequia, Alemania y Polonia; la zona fronteriza entre Austria y Eslovenia; la zona fronteriza entre Croacia y Hungría; la zona fronteriza entre Hungría y Eslovaquia; Ucrania; Berlín; Mostar (Bosnia Herzegovina); la región de los Lagos Prespa (Grecia - Macedonia - Albania); la zona fronteriza entre Albania y Montenegro; la zona fronteriza entre Hungría y Rumanía; Rijeka (Croacia); la zona fronteriza entre Chequia y Eslovaquia; y la región Pomerania (Alemania - Polonia). La edición del año 2020, celebrada entre octubre y noviembre, se ha tenido que realizar de manera telemática a causa de la crisis epidemiológica del COVID - 19.

La enorme diversidad europea, manifestada geográficamente en decenas de territorios de frontera, ha sido plasmada con relativa certeza a lo largo de las diferentes ediciones del proyecto. Mostrando, además, una gran capacidad de análisis conceptual de la frontera, ya que no se trata únicamente de expresar el hecho geográfico, sino también el histórico o identitario. Casos como los de Berlín o Mostar serían claro ejemplo de esto último.

\footnotetext{
42 El nombre completo del proyecto es: "In Between? Searching for Local Histories in Borderlands of Europe" [¿Entre medio? Buscando historias locales en las zonas de frontera de Europa]

${ }^{43}$ Para consultar las diferentes ediciones y sus resultados, acceder a: $\underline{\text { https://enrs.eu/inbetween\#editions }}$
} 
El proyecto cuenta con tres socios estratégicos, cuya participación se entiende en el contexto de apoyo a la cuestión logística y metodológica; son el Archivo Nacional de Cine de Polonia, el Archivo Digital Nacional de Polonia, y la EU Screen Foundation. Se trata de entidades de carácter archivístico y audiovisual, encargadas de dar soporte formativo y cobertura técnica durante el desarrollo del proyecto, así como en la posterior realización del producto final.

A nivel de cada una de las ediciones, éstas se desarrollan también mediante una estrecha colaboración con los socios locales. Serán éstos lo que se encarguen, entre otras cosas, de colaborar con la selección de participantes, de preparar el plan formativo a nivel teórico y técnico, y, en definitiva, de hacerse cargo del buen funcionamiento de todas las cuestiones desarrolladas a lo largo de la estancia de los participantes sobre el terreno. A esta parte se la conoce como "study visit", y en la edición aquí presentada, el European Observatory on Memories (EUROM) fue la entidad que ejerció como socio local.

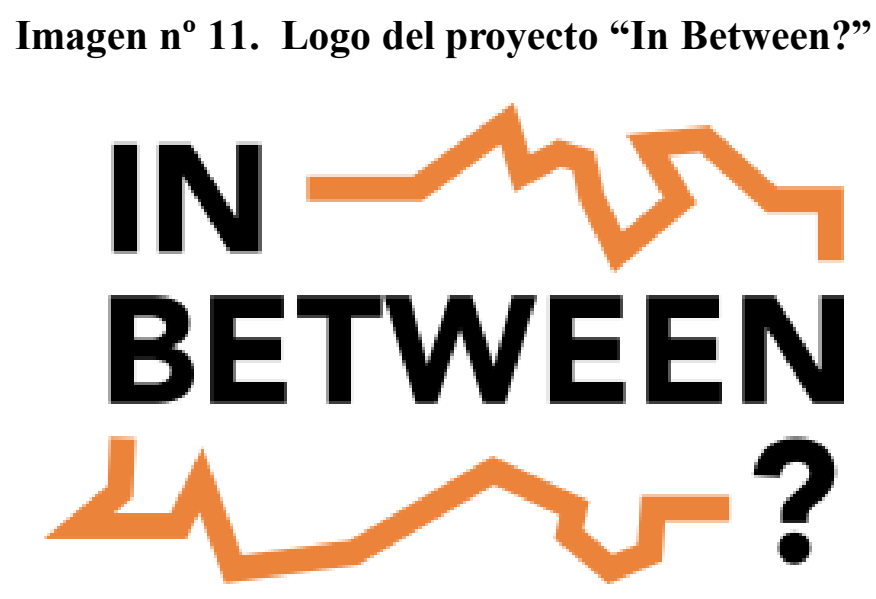

Fuente: ENRS.

\section{Método y vocación del proyecto}

El proyecto "In Between?" nace con la vocación de hacer emerger las memorias de carácter local ubicadas en territorios de frontera a nivel europeo. Su aproximación metodológica potencia la capacidad educativa de la investigación sobre testimonios orales, conjuntamente con el desarrollo de análisis documental gráfico, para acabar disponiendo de un material audiovisual que condense ambas aportaciones en la realización de un documental. 
El alumnado participante en las diferentes ediciones de "In Between?" se organiza de la siguiente manera. En una primera semana de trabajo teórico, llevada a cabo en las instalaciones del ENRS en Varsovia, desarrollan un conjunto de competencias relativas a la investigación documental. El trato con archivos, el análisis de material visual, la metodología de investigación con testimonios orales, o el uso de las diversas herramientas audiovisuales a disposición son las principales materias a trabajar en esta primera semana de aproximación teórica. Con posterioridad se realiza la llamada "study visit", donde cada grupo de estudiantes se dirige al territorio de frontera sobre el cual vaya a desarrollar su trabajo. Allí será donde conozcan los diferentes lugares asociados a la memoria del territorio y entren en contacto con los diferentes protagonistas, es decir, aquellas personas que darán su testimonio oral y cuyas aportaciones supondrán el grueso del material sobre el cual construir el documental final.

El proyecto ejerce como pretexto para que los jóvenes europeos experimenten la "frontera", entendiendo ésta en un sentido amplio que incluya una lectura geográfica, política, cultural, social y generacional. Es también una oportunidad para el descubrimiento de las memorias individuales y colectivas, ubicadas en el contexto de los pasados traumáticos del s. XX, que acaban dotando de identidad a los territorios de frontera ${ }^{44}$.

El concepto de identidad es una de las principales cuestiones trabajadas dentro del proyecto, entendiendo la identidad como el sentido de pertenencia a algún colectivo que se crea en contacto con lo externo a dicho colectivo ${ }^{45}$. En el contexto de la frontera, la cuestión identitaria cobra especial relevancia, pues, aunque exista una línea de demarcación sobre lo que es o no parte de una identidad, ello no implica que dicha marca no pueda ser permeable, moldeable, y a lo largo del tiempo, modificable.

La terminología empleada para la denominación del proyecto, "In Between?" (entre medio), implica que el alumnado participante puede explorar toda una serie de particularidades relativas a esa categoría específica del "entre medio", desde lo más

\footnotetext{
44 Anna Czyzewska, "In Between? An academic introduction". European Network Remembrance and Solidarity, 24 de agosto de 2016. https://enrs.eu/article/in-between-an-academic-introduction

45 Thomas Eriksen, Small Places, Large Issues: An Introduction to Social and Cultural Anthropology. (London: Pluto Press, 2015)
} 
individual y familiar, hasta lo colectivo concerniente a comunidades religiosas, lingüísticas o culturales ${ }^{46}$. La formación de grupos internacionales de trabajo, con estudiantes de diversas nacionalidades, aporta un plus a la manera en la cual las diferentes memorias locales son contempladas y analizadas en el contexto del proyecto. Así, el estudio de ejemplos locales, focalizados en diferentes territorios de frontera europeos, sumado a la experiencia y metodología con proyección internacional, puede llegar a aportar una visión integral de todos aquellos casos tratados en el proyecto.

El concepto de frontera propone, de igual manera, un amplio conjunto de significaciones de carácter didáctico susceptibles de ser tomadas en cuenta en un proyecto de estas características. La variabilidad histórica de las diversas fronteras, así como el significado de las mismas en un mundo globalizado en general, y en Europa en particular, son cuestiones que orientan los diferentes métodos de trabajo y los objetivos didácticos del proyecto.

Independientemente de la cuestión fronteriza, uno de los elementos clave a la hora de analizar identidades "entre medio" tiene que ver con la cuestión migratoria, la cual, obviamente, cobra más importancia en asuntos liminares. En estos contextos se desarrollan las denominadas identidades hibridas ${ }^{47}$, con una parte actual a la que no se pertenece plenamente, y una parte pretérita a la que es imposible retornar. En el caso que nos atañe, el exilio republicano, puede verse claramente esta relación, donde la imposibilidad de retornar a la España franquista en muchos casos significó el asumir esa identidad híbrida francoespañola.

La aproximación al estudio del pasado realizada desde el proyecto plantea un uso escalado de la microhistoria, tomando en cuenta todas aquellas particularidades personales o familiares de los contextos de frontera. Así, a través de todas esas memorias puede accederse a la construcción de un relato estructurado de carácter más general e inclusivo del territorio. Ciertamente, mientras se documentan y analizan las diferentes historias individuales, familiares y locales, nunca debe perderse el foco epistemológico de unión entre historia y memoria. En tanto que la memoria implica la representación del pasado en el presente, y la construcción de la identidad se valora aquí

\footnotetext{
${ }^{46}$ Anna Czyzewska, "In Between? ...", op. cit.

47 Jorge Luis Andrade Fernandes, Challenging Euro-America's Politics of Identity: The Return of the Native. (London: Routledge, 2008)
} 
como un elemento de actualidad, el enfoque desde la memoria es clave para la construcción de los relatos identitarios del presente.

Tomando en cuenta estas premisas generales, basadas en el análisis de las identidades de carácter local, cada uno de los casos de aplicación del proyecto "In Between?" se desarrolla con total libertad para que los participantes decidan qué elementos es necesario tratar para un correcto desarrollo de su experiencia.

La base metodológica para el desarrollo del proyecto se basa en la historia oral, a través del conjunto de testimonios y sus aportaciones. La grabación y transcripción de las entrevistas permite aproximarse a la historia a través de los ojos individuales del testimonio. Paralelamente, se construye una narrativa general basada en confrontar y contrastar los datos de la memoria oral con los diferentes inputs multidisciplinares, de tipo teórico y de tipo aplicado, recibidos durante la "study visit".

De entre las diferentes aproximaciones metodológicas complementarias al desarrollo de la grabación de los testimonios, encontramos un conjunto de técnicas enmarcadas en la etnografía y la antropología. Tales serían, por ejemplo, el análisis cualitativo de biografías y autobiografías, las entrevistas abiertas y cerradas, o las denominadas como prácticas de recuerdo o memoria. En este último enfoque metodológico entrarían las diferentes actividades destinadas a la salvaguarda y transmisión del pasado. A nivel familiar, ello se manifiesta a través de los archivos y recuerdos personales, siendo los álbumes fotográficos y otros objetos de similar valor sentimental, un buen material de inspiración para la realización de actividades con un gran potencial didáctico.

A lo largo de la semana de trabajo teórico, pues, el alumnado participante obtiene las herramientas necesarias para el correcto desarrollo de su "study visit", donde aplicará sus conocimientos y acabará de dar forma al producto final de su trabajo: el documental audiovisual. En el caso aquí analizado, la frontera oriental francoespañola, la memoria del exilio republicano será el principal elemento argumental para el desarrollo del trabajo de los participantes.

\section{La experiencia "In Between?" en el territorio catalán transfronterizo}


Habría que remarcar, de entrada, que las particularidades de la memoria del territorio han dotado a esta experiencia de una profundidad histórica remarcable. Así, en otras muchas ediciones se ha tomado en cuenta la microhistoria o las memorias orales de carácter individual o familiar, mientras que aquí, como veremos, ha sido un gran sujeto histórico y memorial como el exilio republicano lo que ha dotado de estructura a la edición y al resultado final de la misma, editado en formato de documental audiovisual.

Al hilo de la cuestión metodológica, pues, es importante reseñar de qué manera la singularidad del territorio, y en concreto la existencia de una vasta topografía memorial, acaban dando forma al plan de trabajo de la "study visit". El trabajo con el testimonio es la principal herramienta a desarrollar en el proyecto, de eso no hay duda, y, como tal, así se tiene en cuenta a nivel genérico en todas las ediciones de "In Between?" y en todas sus "study visits". En este caso, sin embargo, al tratar en profundidad sobre una cuestión de carácter histórico con una fuerte relación con la memoria colectiva, se ha considerado oportuno incorporar al corpus metodológico del proyecto el trabajo "in situ". De esta manera, aprovechando la existencia del conjunto de lugares de memoria del exilio republicano, se diseñó un plan de trabajo en el que patrimonio y testimonio dispondrían de un protagonismo parejo, posibilitando una retroalimentación mutua capaz de orientar favorablemente el desarrollo del trabajo de campo y su posterior labor de análisis.

La edición de "In Between?" dedicada a la frontera oriental francoespañola se desarrolló en otoño de 2017, en el marco de la segunda edición del proyecto. Como se ha comentado con anterioridad, la metodología estructural de "In Between?" establece que cada grupo de trabajo, tras culminar la semana de formación teórica sobre archivística, técnica audiovisual, trabajo con el testimonio, etc. se desplaza sobre el terreno para aplicar los conocimientos adquiridos. El grupo de estudiantes seleccionado para la ocasión estaba formado por 5 personas: 3 de nacionalidad española ( 2 de Cataluña y 1 de Madrid), 1 de nacionalidad francesa, y 1 de nacionalidad polaca. Durante la semana dedicada a la "study visit", pues, se desarrolló un programa de trabajo mediante el cual se visitaría una gran mayoría de los espacios de memoria del territorio catalán transfronterizo. Dichos espacios, como se ha mencionado también en apartados anteriores, nos remiten a memorias diversas de la época comprendida entre 
los años de la Guerra Civil y la Segunda Guerra Mundial, aunque siempre percibiendo el exilio republicano como la principal pieza estructural de su narrativa y de su proceso de puesta en valor.

Organizativamente, el organismo que ejerció como socio local gestor de la presente edición fue el Observatorio Europeo de Memorias de la Fundación Solidaridad UB. Un organismo estructurado en forma de red internacional de carácter europeo, con sede en la Universidad de Barcelona, cuya vocación reside en la promoción, difusión y gestión de diferentes proyectos relacionados con la memoria a nivel, local, regional e internacional. Así, desde el Observatorio Europeo de Memorias (EUROM, por sus siglas en inglés - European Observatory on Memories) ${ }^{48}$, se organizó el conjunto de instituciones que formarían parte del partenariado local, las cuales, en diferentes grados, darían soporte a la edición en materias como la logística o la difusión, entre otras. E1 Museu Memorial de l'Exili (MUME) de la Jonquera, sería el principal ente colaborador sobre el terreno, ejerciendo como campamento base para el conjunto de actividades realizadas a lo largo de la semana de duración de la "study visit". Otras entidades colaboradoras fueron la Asociación de descendientes del exilio republicano FFREEE (Fils et Filles de Républicains Espagnols et Enfants de l'Exode), la Associació Passatges de Cultura Contemporània, la Asociación Trajectoires, y los ayuntamientos de Argelèssur-Mer y Elne. De esta manera, el conjunto del partenariado aportaba un bagaje multiexperiencial en los campos de la administración, del patrimonio y de la educación, con estrecha relación con el territorio y con la memoria del exilio republicano.

A medida que se desarrollaba el programa de visitas, se iban realizando, de manera paralela, las entrevistas a las diferentes personas que ejercían como testimonios, en base a las experiencias de las cuales acabaría tomando forma el documental audiovisual final. Para la selección de los testimonios orales, se tomó en cuenta la existencia de perfiles relacionados con la memoria del exilio republicano desde diferentes aproximaciones, de manera que los 8 protagonistas finalmente seleccionados pudieran complementarse según la especificación de cada perfil. Siete de los 8 testimonios son protagonistas directos o descendientes de protagonistas directos del exilio republicano, entre los cuáles, además, hay perfiles de relevancia a nivel político y

\footnotetext{
${ }^{48}$ En la página web del EUROM puede consultarse el conjunto de proyectos y actividades realizados y en marcha: https://europeanmemories.net/
} 
educativo. La única persona sin relación directa con el exilio pertenece al mundo educativo $\mathrm{y}$ ha sido $\mathrm{y}$ es una de las principales promotoras de un gran número de proyectos sobre la memoria del exilio en el sur de Francia. La relación de testimonios es la siguiente: Margaret Townsend (descendiente del exilio y empleada del MUME), Gilbert Susagna (exiliado e integrante del FFREEE) ${ }^{49}$, Emita Díaz de Begar (descendiente del exilio e integrante del FFREEE), Rose Aylagas (exiliada e integrante del FFREEE), Serge Barba (descendiente del exilio e integrante del FFREEE) ${ }^{50}$, Queti Otero (descendiente del exilio e integrante de Trajectoires), Nicolás García (descendiente del exilio y político local), y Sonia Serradeil (profesora de historia e integrante de Trajectoires).

El planteamiento discursivo sobre el cual se desarrollaría el trabajo con el testimonio, y que acabaría dando estructura al documental audiovisual final, sería consensuado y decidido por el propio grupo de estudiantes. Tomando como estructura principal el elemento histórico y memorial del exilio republicano español, se considerarían de manera relevante otras categorías a ejercer como dimensiones analíticas en el contexto de la grabación de las entrevistas, tales como la identidad, la memoria o la triple dialéctica entre pasado, presente y futuro. La exploración de estas tres dimensiones analíticas, junto a la referencia integral del exilio republicano, dotarían al documental final de su estructura narrativa.

La identidad, elemento protagónico a nivel genérico en la metodología "In Between?", dispone de una capacidad intrínseca para forjar narrativas memoriales si se analiza de manera adyacente a la propia historia del territorio. Así, el análisis de los procesos sociales acaecidos de manera dual en los territorios divididos por una frontera, ayuda a comprender el desarrollo identitario de ambos lados de la misma, y pone de manifiesto los puntos de unión por encima de los elementos divisorios.

La memoria, entendida como imagen del pasado ubicada en el presente, será lo que dote de relevancia a las reflexiones aportadas por los testimonios. Desde la historia es posible avanzar, $\mathrm{y}$, de hecho, se avanza, en la construcción de un presente favorecido por el conocimiento del pasado. Sin embargo, la memoria está constantemente

\footnotetext{
${ }^{49}$ Internado en el campo de Argelès-sur-Mer junto a su madre.

${ }^{50}$ Uno de los bebés nacidos en la Maternidad de Elne.
} 
dialogando entre pasado y presente, de manera que no existe un punto final en dicha dialéctica. De esta manera, las representaciones patrimoniales tomadas en cuenta para el documental, junto con los diferentes testimonios aportados de viva voz, ayudan a dar recorrido a la memoria del exilio republicano más allá de su propia divulgación histórica.

Como herramienta de conexión entre pasado y presente, pues, la memoria y su estudio van más allá del mero conocimiento. A través del análisis de las complejidades del pasado y de sus diferentes proyecciones en el presente, trabajar la memoria nos habilita para perfilar estrategias que ayuden a preparar un futuro de respeto $\mathrm{y}$ de convivencia. Por ello se ha tomado la cuestión dialéctica entre pasado, presente y futuro, como elemento analítico en el proceso de grabación de los testimonios y de ensamblaje del documental. En un presente repleto de procesos de enorme complejidad política (conflicto catalán, auge de la extrema derecha, crisis de refugiados...), la referencia del exilio republicano y su memoria puede ser tomada en cuenta como pauta para la construcción nuevos discursos memoriales donde la democracia y los derechos humanos sean sus pilares estructurales.

El resultado final es el mencionado documental audiovisual, de acceso libre a través de la plataforma Youtube ${ }^{51}$, además de un conjunto de materiales de archivo resultantes de la intensa semana de trabajo ejecutada durante la "study visit". Destaca en este sentido el archivo de material gráfico de un total de 746 imágenes, así como más de 12 horas de duración de material audiovisual. Se trata de documentación accesible mediante demanda en alguna de las instituciones colaboradoras, como el EUROM o el MUME, además del propio organismo organizador del proyecto “In Between?", el ENRS de Polonia.

\footnotetext{
51 El documental audiovisual resultante puede ser visualizado en este link: https://www.youtube.com/watch?v=WdIx3ph4mbs\&feature=emb title
} 


\section{Imagen no 12. Imagen promocional de la edición de "In Between?" en el territorio catalán transfronterizo}

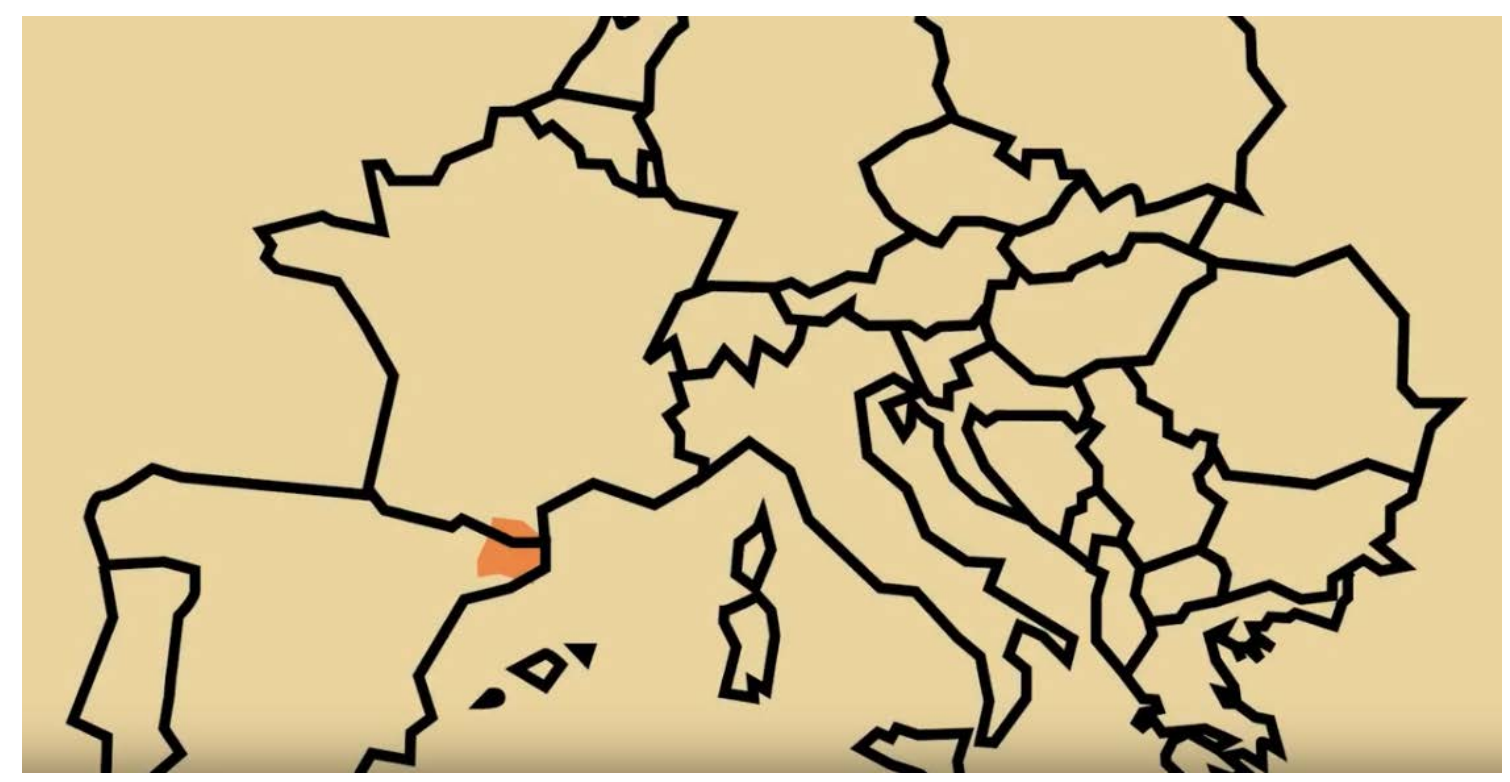

Fuente: ENRS.

\section{CONSIDERACIONES FINALES}

El exilio republicano español es un episodio histórico, a caballo entre la Guerra Civil española y la Segunda Guerra Mundial, cuya relevancia se manifiesta en las numerosas investigaciones existentes en el campo de la ciencia histórica y de otras ciencias sociales. Los nuevos caminos que las ciencias sociales ponen a disposición de la investigación en el s. XXI, ensanchan sobremanera los enfoques clásicos, de manera que una cuestión explorada con relativa profundidad desde la ciencia histórica pueda ser abordada desde prismas nuevos e innovadores que colaboren en el avance del conocimiento histórico de dicho sujeto.

El mundo digital es una buena prueba de ello. La eclosión dentro del ámbito educativo y patrimonial de las herramientas digitales de última generación ha aportado al estudio del exilio republicano español nuevas aproximaciones que suponen un efecto multiplicador sobre el impacto de otras investigaciones consolidadas con anterioridad. Nuevos usos, socialmente arraigados en relación al mencionado mundo digital, ejercen también como influencia para la innovación y el desarrollo de nuevas líneas de 
investigación, como sería el caso de las redes sociales y la diversidad de proyectos e iniciativas en el ámbito de la educación y la investigación.

En el campo patrimonial, se ha asistido también en las últimas décadas a un proceso generalizado de puesta en valor del conjunto de espacios de memoria del exilio republicano, ubicados tanto del lado francés como del español. Del lado español, en el marco de unas incipientes políticas públicas de memoria planteadas por el gobierno autonómico catalán, ha sido posible implementar una acción de identificación, clasificación y valorización de sus espacios de memoria democrática. Dentro del conjunto de categorías de dichos espacios sobresalen, tanto numérica como conceptualmente, aquellos relacionados con el exilio republicano. La importancia del hecho histórico y su impacto transfronterizo proyectan hoy día la existencia de una rica y variada topografía memorial, donde el exilio republicano y los diferentes episodios históricos y memoriales con él relacionados son protagonistas.

El contexto de la Europa común, donde se fomenta el trabajo cooperativo entre los diferentes estados miembros, promociona la existencia de políticas de memoria conjuntas donde el campo patrimonial es protagonista. A su vez, la eclosión y consolidación de los diferentes recursos existentes a partir de la potenciación de las nuevas tecnologías, abre un horizonte de nuevas posibilidades para el tratamiento del pasado común europeo, así como de los diferentes pasados locales integrados en el contexto continental general. La existencia de instituciones como el ENRS o el EUROM, respectivas impulsoras del proyecto “In Between?” y de su edición local aquí presentada, debe entenderse en dicho contexto. Lo vocación europeísta de las políticas de memoria sale reforzada a través de las sinergias entre territorio, patrimonio y nuevas tecnologías.

Así, la edición local del proyecto "In Between?" expuesta en el presente texto, pone de manifiesto el potencial educativo que surge de la sinergia entre patrimonio, testimonio y herramientas digitales. Aplicado a un sujeto histórico y memorial consolidado como el del exilio republicano, ello implica el acercamiento a nuevos públicos que hasta entonces tenían un acceso menor a las prácticas de divulgación memorial. Se trata, además, de un acercamiento dual, donde esos nuevos públicos tienen acceso en tanto que protagonistas de la investigación, como es el caso de los 
participantes directos en el proyecto, así como en su rol de público objetivo sobre el cual incidir en la difusión memorial del exilio republicano.

La eclosión y consolidación de las herramientas digitales a disposición del patrimonio memorial se ha manifestado de manera muy exitosa en este caso, acercando la reflexión crítica sobre el exilio republicano a un público emergente en el marco geográfico de todo el continente europeo. Así, patrimonio, territorio, historia y memoria emergen como una nueva referencialidad integral cuyo impacto y capacidad didáctica garantiza recorrido a este tipo de iniciativas.

\section{BIBLIOGRAFÍA}

Andrade Fernandes, Jorge Luis. Challenging Euro-America's Politics of Identity: The Return of the Native. London: Routledge, 2008

Balfour, Sebastian. "España desde 1931 hasta hoy", en Historia de España, editado por Raymond Carr, 249-292. Barcelona: Península, 2007.

Brown, T.H. "Beyond constructivism: navigationism in the knowledge era". On the Horizon; $\mathrm{n}^{\circ} 14$, (2006): pp. 108-120.

Calvet, Josep. Les muntanyes de la llibertat. El pas d'evadits pels Pirineus durant la Segona Guerra Mundial 1939-1944. Barcelona: L’Avenç, 2008.

Camiade, Martine. "Territori, Paisatge i Exili. Rosselló 1939: Allò Viscut d'una Crisi Humanitària a partir de les Fonts Orals". En Reflexionant l'Exili: Aproximació a l'Exili Republicà: Entre la Historia, l'Art i el Testimoniatge, dirigido por Jordi Font, pp: 49-62. Catarroja: Editorial Afers, 2010.

Castaner, Tristan. Femmes en exil, mères des camps. Élisabeth Eidenbenz et la maternité suisse d'Elne (1939-1944). Perpinyà: Éditions Trabucaire, 2008.

Clara, Josep. “Camps de reclusió, camps de concentración”. En L'exili republicà als Països Catalans. Una diàspora històrica, dirigido por Pelai Pagés, pp: 109-136, Barcelona: Ed. Base, 2015.

Coma Quintana, Laia. "Dinamizar y digitalizar la ciudad: itinerarios urbanos, dispositivos móviles y códigos QR". Her\&Mus. Heritage \& Museography, n. ${ }^{\circ} 13$ (2013): $\quad$ pp. 63-68. URL: https://www.raco.cat/index.php/Hermus/article/view/313395 [Consulta: 9-102020].

De Castro Martín, Pablo, y Sánchez-Macías, Inmaculada. “\#Souvenirs1936. Transmedia y procesos de identización en el aprendizaje". Revista Interuniversitaria de Formación del Profesorado, n94, (2019): pp. 63-82. 
Dreyfus-Armand, Geneviève. El exilio de los republicanos españoles en Francia. Barcelona: Crítica, 2000.

Eiroa San Francisco, Matilde. "Memoria e historia en redes sociales: nuevos soportes de resistencia al olvido de la Guerra Civil española y el Franquismo". Historia y memoria, $\quad \mathrm{n}^{\circ} 21$, (2020): $\quad$ pp. https:/doi.org/10.19053/20275137.n21.2020.9659.

Eriksen, Thomas. Small Places, Large Issues: An Introduction to Social and Cultural Anthropology. London: Pluto Press, 2015.

Font, Jordi. "A cavall de la història i la memòria: el Museu Memorial de l'Exili de la Jonquera-MUME", Mnemosine: revista catalana de museologia, $\mathrm{n}^{\mathrm{o}} 5$ (2009): pp. 105-113.

Font, Jordi.; González, David.; Domènech, Gemma. y Marquès, Salomó. "La memoria del exilio republicano a través de sus espacios: patrimonio, turismo y museos en el territorio catalán transfronterizo". En Lugares de memoria traumática. Representaciones museográficas de conflictos políticos y armados, editado por I. Arrieta, pp. 71-98. Bilbao: UPV/EHU Servicio Editorial, 2016.

Forcada, Eric. De la chute de Barcelone à la Retirada : Report of Wide World Photo for the New York Times. Perpignan: Mare Nostrum, 2014.

Foucher, Michel. Fronts et Frontiers: Un Tour du Monde Géopolitique. Paris: Fayard, 1991.

González, David. y Font, Jordi. "La museización del patrimonio memorial transfronterizo: el caso del exilio republicano y sus espacios". MIDAS - Museus e estudos interdisciplinares, $\mathrm{n}^{\mathrm{0}} 6, \quad$ 2016: pp. 1-17. DOI: https://doi.org/10.4000/midas.1030

González Vázquez, David. "La práctica turística como mecanismo de transmisión de valores: Cataluña y los lugares de memoria democrática". RITUR - Revista Iberoamericana de Turismo, $\mathrm{n}^{\circ} 4$ especial, (2014): pp. 36-49.

-- "La patrimonialización de la memoria histórica: entre el deber social y la estrategia turística. Apuntes sobre el caso catalán". PASOS - Revista de Patrimonio y Turismo Cultural, vol. 5, nº14, (2016): pp. 1267-1280.

-- "El turismo de memoria y las implicaciones de la frontera: una aproximación teórica desde los Pirineos". En Politiques memorials, fronteres i turisme de memoria, editado por Ramon Arnabat y Montserrat Duch, pp. 97-114. PerpinyàTarragona: PUP-PURV, 2017.

Guixé, Jordi. "El Memorial Democrático y los lugares de la memoria: la recuperación del patrimonio memorial en Cataluña". Entelequia, nº 7, (2008): pp. 217-228.

-- "Espacios, memoria y territorio, un memorial en red en Cataluña". En El Estado y la memoria: Gobiernos y ciudadanos frente a los traumas de la historia, dirigido por Ricard Vinyes, pp. 569-608. Barcelona: RBA Libros, 2009.

Jelin, Elizabet. y Langland, Victroia. (Comps.) Monumentos, memoriales y marcas territoriales. Madrid - Buenos Aires: Siglo XXI, 2003. 
Ley 52/2007, de 26 de Diciembre, por la que se reconocen y amplían derechos y se establecen medidas a favor de quienes padecieron persecución o violencia durante la guerra civil o la dictadura, BOE n³10, p. 53.410 (2007).

Llei 13/2007, del 31 d'octubre, del Memorial Democràtic, DOGC no 5006, p. 45.172 (2007).

Llombart, Maria. "Sobre memòries, el "Memorial Democratic" (2007-2011), ¿un projecte sense futur?". Tropelias: Revista de teoría de la literatura y literatura comparada, $\mathrm{n}^{\mathrm{o}} 22$, (2014): pp. 58-69.

López Benito, Victoria; Santacana Mestre, Joan. "Cultura digital, museos y educación”. Her\&Mus. Heritage \& Museography, , n. ${ }^{\circ}$ 13, (2013): pp. 8-15. URL: https://www.raco.cat/index.php/Hermus/article/view/313342 [Consulta: 910-2020].

Luzi, Federica. "Entre narrations et expériences. Les usages du passé des réfugiés espagnols en France". Tesis doctoral, París - EHESS, 2016.

Martínez Puig. Alfons. "La postguerra del Patrimoni Artístic a l'Alt Empordà febrersetembre 1939", Annals de 1'Institut d'Estudis Empordanesos, no 45, (2014): pp. 143-174.

Peschansky, Denis. La France des camps. L'internement, 1938-1946. París: Gallimard, 2002.

Pujol, Enric. "El Museu de l'Exili de La Jonquera". Mnemosine: revista catalana de museologia, $\mathrm{n}^{\mathrm{o}} 1$, (2003): pp. 67-78.

-- "El Cas Català com a Paradigma”. Mirmanda, n³, (2008): pp. 26-28.

-- "Projectes culturals transfronterers: el cas de l'exili republicà de 1939". Mirmanda, nº 4, (2009): pp. 74-84.

Riera Miralles, Ferran. "Valorització patrimonial de la mina Canta de la Vajol mitjançant una proposta aplicada de turisme cultural". Trabajo de Fin de Máster, Universitat de Girona, 2016. http://hdl.handle.net/10256/13895

Saz, Ismael "El "moment memòria". Justícia, veritat i reconciliació democràtica". Afers: fulls de recerca i pensament. Vol. 22, nº56, (2007): pp. 27-40.

Schlögel, Karl. En el Espacio Leemos el Tiempo: Sobre la Historia de la Civilización y Geopolitica. Madrid: Ediciones Siruela, 2007.

Serrano, Miquel. "El mas Perxés d'Agullana, espai de memòria de la retirada". Annals de l'Institut d'Estudis Empordanesos, n41, (2010): 51-75.

Silva, Emilio "Movimiento memorialista (E1 contexto de la memoria)". En Diccionario de memoria histórica. Conceptos contra el Olvido, coordinado por Rafael Escudero, pp. 69-75. Madrid: Los Libros de la Catarata, 2011.

Sierra Blas, Verónica. "El diálogo que nunca cesa: El archivo de los lectores/as de Antonio Machado en Collioure". Comunicación presentada en $80^{\circ}$ Aniversario de la muerte de Antonio Machado, Collioure, 24/02/2019. URL: http://www.machado-collioure.fr/wp-content/uploads/2019/02/VSBCONFERENCIA-HOMENAJE-FAM-2019.pdf 
Tuban, Gregory. Les séquestrés de Collioure. Un camp disciplinaire au Chateau Royal en 1939. Perpignan: Editions Mare Nostrum, 2003.

Vinyes, Ricard. "La memoria del Estado". En El Estado y la memoria: gobiernos y ciudadanos frente a los traumas de la historia, dirigido por Ricard Vinyes, pp. 23-66. Barcelona: RBA Libros, 2009.

-- "Memoria, democracia y gestión”. História e Perspectivas, n54, (2016): pp. $11-22$.

\section{WEBS CITADAS:}

European Network Remembrance and Solidarity. URL: https://enrs.eu/article/inbetween-an-academic-introduction.

European Network Remembrance and Solidarity. URL:

https://enrs.eu/inbetween\#editions

European Observatory on Memories. URL: https://europeanmemories.net/ 